\title{
Lesions of the Amygdala That Spare Adjacent Cortical Regions Do Not Impair Memory or Exacerbate the Impairment Following Lesions of the Hippocampal Formation
}

\author{
Stuart Zola-Morgan, ${ }^{1}$ Larry R. Squire, ${ }^{1}$ and David G. Amaral ${ }^{2}$ \\ 'Veterans Administration Medical Center, San Diego, California 92161, and Department of Psychiatry, University of \\ California, San Diego, La Jolla, California 92093, and ${ }^{2}$ The Salk Institute, San Diego, California 92138
}

\begin{abstract}
Monkeys with stereotaxic lesions of the amygdaloid complex that spared the surrounding cortex (i.e., the periamygdaloid, entorhinal, and perirhinal cortices) performed normally on the delayed nonmatching to sample task, as well as on 3 other memory tasks (object retention, concurrent discrimination, and delayed response) administered during the $1 \frac{112}{2}$ years after surgery. These animals also performed normally on pattern discrimination and motor-skill learning, 2 tasks analogous to ones amnesic patients perform well. A second group of monkeys with conjoint lesions that included both the amygdaloid complex, as just described, and the hippocampal formation were impaired on the same 4 memory tasks. However, the severity of impairment in this group was no greater than in monkeys with lesions of the hippocampal formation alone. Thus, circumscribed bilateral lesions of the amygdala did not impair performance on 4 different memory tasks, nor did they exacerbate the memory impairment that followed hippocampal formation lesions alone. These findings suggest that one must look to structures other than the amygdala to account for the severe memory impairment that follows large lesions of the medial temporal region. One possibility is that damage to the cortical regions that surround the amygdala contributes to memory impairment.
\end{abstract}

Bilateral damage to the medial temporal region of the brain causes profound amnesia in humans (Scoville and Milner, 1957; Penfield and Milner, 1958). One approach to determining which neural connections and structures in the medial temporal region must be damaged to produce amnesia is based on the recent development of an animal model of human amnesia in the monkey (Mishkin, 1982; Squire and Zola-Morgan, 1983; Mahut and Moss, 1984). The lesion in the monkey that first established the animal model was intended to approximate the surgical removal sustained by the well-studied amnesic patient H.M. This lesion, which we have termed the $\mathrm{H}^{\prime} \mathrm{A}^{\prime}$ lesion (Squire and Zola-Morgan, 1988), involved the amygdala and the hippocampus (including the dentate gyrus and subicular complex), as well

\footnotetext{
Received Aug. 9, 1988; revised Oct. 24, 1988; accepted Oct. 25, 1988.

Supported by the Medical Research Service of the Veterans Administration, NIH Grants NS19063, NS16980, and MH41479, NSF Grant BSN85-12349, the Office of Naval Research, and the McKnight Foundation. We thank Carol Micheletti, Jasmine Allen, and Michael Mesches for behavioral testing; and Cecelia LeClair and Janet Weber for histological assistance.

A research protocol describing all aspects of the present study that relate to the use of animais (care and maintenance, surgery, behavioral testing and euthanasia) was approved by the Animal Research Committees of the V. A. Medical Center, San Diego, and the University of California, San Diego.

Correspondence should be addresed to Stuart Zola-Morgan, Veterans Administration Medical Center, 3350 La Jolla Village Drive, San Diego, CA 92161.
}

Copyright (C) 1989 Society for Neuroscience $0270-6474 / 89 / 061922-15 \$ 02.00 / 0$ as adjacent cortical regions. In our notation, $\mathrm{H}$ refers to the hippocampus, A to the amygdala, and + to adjacent cortical tissue.

Monkeys with $\mathrm{H}^{+} \mathrm{A}^{+}$lesions exhibit severe memory impairment on a number of tasks (Mishkin, 1978; Mahut et al., 1981; Zola-Morgan and Squire, 1984, 1985) that human amnesic pa tients also fail (Aggleton et al., 1988; Squire et al., 1988). As in human amnesia, the impairment in monkeys is multimodal (Murray and Mishkin, 1984). It is also selective, because skillbased memory is intact (Zola-Morgan and Squire, 1984), and it is enduring, remaining unchanged for at least $1 \frac{1 / 2}{2}$ years after surgery (Zola-Morgan and Squire, 1985).

Significant memory impairment is also observed following less extensive damage to the medial temporal region. Thus, memory impairment is readily detected following bilateral damage limited to the hippocampal formation (Mahut et al., 1982; Zola-Morgan and Squire, 1985; Zola-Morgan et al., 1989). This lesion $\left(\mathrm{H}^{+}\right)$-which involves the hippocampus, dentate gyrus, subicular complex, posterior entorhinal cortex, and much of the parahippocampal gyrus - produces less severe memory impairment than the $\mathrm{H}^{+} \mathrm{A}^{+}$lesion (Mishkin, 1978; Zola-Morgan et al., 1989). This finding is consistent with the fact that patient R.B., who had bilateral damage limited to the CA1 field of the hippocampus (Zola-Morgan et al., 1986), was not as impaired as patient H.M., who had more extensive medial temporal lobe damage.

The question arises as to why the $\mathrm{H}^{+} \mathrm{A}^{+}$lesion produces more memory impairment than the $\mathrm{H}^{+}$lesion. One possibility is that severe memory impairment depends on damage to the amygdala, which occurs in the $\mathrm{H}^{+} \mathrm{A}^{+}$lesion but not in the $\mathrm{H}^{+}$lesion (Mishkin, 1978; Saunders et al., 1984; Bachevalier et al., 1985; Murray and Mishkin, 1986). Recent neuroanatomical information supports the possibility that the amygdala could be important in cognitive functions. In addition to its substantial connections with the hypothalamus and the brain stem, the amygdaloid complex has prominent projections to the thalamus and neocortex, hippocampal formation, major portions of the striatum, and several cell groups of the basal forebrain including the cholinergic cells of the basal nucleus of Meynert. Thus, the amygdaloid complex appears to be an interface between hypothalamic and brain-stem structures and many limbic and neocortical regions (Weiskrantz, 1956; Gloor et al., 1981; Mishkin and Aggleton, 1981; Mishkin, 1982; for review, see Amaral, 1987).

Amygdala damage, however, is not the only component of the $\mathrm{H}^{+} \mathrm{A}^{+}$lesion that distinguishes this lesion from the $\mathrm{H}^{+}$lesion. The surgical procedure ordinarily used to remove the amygdala in monkeys involves an anterior approach that necessarily dam- 
ages cortical tissue such as the periamygdaloid, entorhinal, and perirhinal cortices, which are adjacent to the amygdala. All published histological descriptions of $\mathrm{H}^{+} \mathrm{A}^{+}$lesions in the monkey that were made using an anterior surgical approach describe damage to adjacent extra-amygdala cortical regions. In addition, the surgical procedure used for patient H.M. (Scoville et al., 1951) would also have resulted in damage to cortical tissue adjacent to the amygdala. Accordingly, it is difficult to conclude that damage to the amygdala itself is the reason why more severe impairment occurs following the $\mathrm{H}^{+} \mathrm{A}^{+}$lesion than following the $\mathrm{H}^{+}$lesion.

The present study investigated the effects on memory of damage limited to the amygdala. We evaluated the severity of memory impairment in 2 new operated groups. One group of monkeys received a lesion that damaged all the components of the amygdaloid complex bilaterally but spared the surrounding cortex (the A lesion). A second group of monkeys received a bilateral lesion of the hippocampal formation in combination with a circumscribed lesion of the amygdaloid complex (the $\mathrm{H}^{+} \mathrm{A}$ lesion). The performance of these 2 groups was compared to the performance of a third group of previously studied monkeys (Zola-Morgan and Squire, 1986; Zola-Morgan et al., 1989) with lesions limited to the hippocampal formation $\left(\mathrm{H}^{+}\right)$. These 3 groups and normal control group $(\mathrm{N})$ were tested on the delayed nonmatching to sample task, which has become a standard task for cvaluating momory in the monkcy. They were also tested on 3 other tasks sensitive to human amnesia and on 2 tasks analogous to ones that amnesic patients perform well.

\section{Materials and Methods}

\section{Subjects}

Twelve cynomolgus monkeys (Macaca fascicularis) were used, all weighing between 3.7 and $4.5 \mathrm{~kg}$ at the beginning of the study. Based on weight-and-age tables (Hartley et al., 1984; Szabo and Cowan, 1984), these monkeys were estimated to be 4-5 years old (young adults). The 12 monkeys belonged to 4 experimental groups $\left(\mathrm{A}, \mathrm{H}^{+} \mathrm{A}, \mathrm{H}^{+}\right.$, and $\left.\mathrm{N}\right)$. Three monkeys (all males) received bilateral lesions of the amygdala (A). These lesions were intended to spare cortical regions surrounding the amygdala, i.e., the anterior entorhinal cortex, perirhinal cortex, and periamygdaloid cortex.

Three other male monkeys received bilateral conjoint lesions of the amygdala and hippocampal formation, including the hippocampus proper, the dentate gyrus, subicular complex, posterior entorhinal cortex, and parahippocampal gyrus $\left(\mathrm{H}^{+} \mathrm{A}\right)$. The damage to the hippocampal formation in this group was intended to approximate the damage in animals that were prepared for previous studies (cf. Mishkin, 1978; Zola-Morgan and Squire, 1986).

Three female monkeys received bilateral lesions limited to the hippocampal formation $\left(\mathrm{H}^{+}\right)$. This lesion was the same as the lesion intended for the $\mathrm{H}^{+} \mathrm{A}$ group, as just described, except that the amygdala was spared. Behavioral data for this group have been presented as part of 2 previous reports (Zola-Morgan and Squire, 1986; Zola-Morgan et al., 1989). Finally, 3 monkeys ( 2 males, 1 female) were unoperated and comprised a normal control group (N). Behavioral data for these monkeys were also reported previously (Zola-Morgan et al., 1989). Monkeys were maintained on a daily ration of Purina Monkey Chow, supplemented with fruit and chewable vitamin C tablets $(250 \mathrm{mg})$.

\section{Surgery}

All surgery was performed under sodium pentobarbital anesthesia (30 $\mathrm{mg} / \mathrm{kg}$ ). Figure 1 illustrates the intended lesions for each of the 3 operated groups. Lesions of the amygdala were made using a stereotaxic approach. A radio frequency (rf) lesion maker (Grass, model LM-2) was used in combination with a specially designed electrode, $0.5 \mathrm{~mm}$ in diameter, with a tapered tip exposed for $2 \mathrm{~mm}$. Lesion parameters were first established in 2 pilot animals. With the monkey's head held in the stereotaxic instrument, a small dental burr was used to thin the skull along the midline at AP 17.5 (Szabo and Cowan, 1984) until the sagittal sinus could be viewed. The electrode tip was then positioned at the middle of the width of the sinus, and the mediolateral 0 point was recorded. The AP and ML coordinates for positioning the electrode were determined from the atlas of Szabo and Cowan (1984). Two small craniotomies were then made, one on each side of the midline, centered approximately $9 \mathrm{~mm}$ lateral to the sinus. The openings extended for 10 $\mathrm{mm}$ in the anterior-posterior direction and $5 \mathrm{~mm}$ in the mediolateral direction. A dural flap was made, and the tip of the rf electrode was then positioned over one of the openings. Landmarks at the base of the cranium predict the position of forebrain structures such as the amygdala more accurately than the position of the auditory meatus (Aggleton and Passingham, 1981; Szabo and Cowan, 1984; Aggleton, 1985). Accordingly, the $\mathrm{rf}$ electrode was lowered to the base of the cranium, and the dorsal-ventral (DV) coordinates for the amygdala lesion were calculated relative to the base of the cranium. Four lesions of the amygdala were made on each side of the brain. Separate lesions were made in the dorsal (AP 18.5; ML 9.5; DV - 6.5 above the ventral surface of the brain) and in the ventral (AP 18.5; ML 9.5; DV -4.0) portions of the anterior extent of the amygdala, and separate lesions were made in the dorsal (AP 17.0; ML 9.0; DV -6.5) and ventral (AP 17.0; ML 9.0; DV - 4.0) portions of the posterior extent of the amygdala. At each coordinate, the tip of the electrode was brought to a temperature of approximately $80^{\circ} \mathrm{C}$ for $45 \mathrm{sec}$.

For the $\mathrm{H}^{+} \mathrm{A}$ lesions, monkeys first sustained bilateral $\mathrm{rf}$ lesions of the amygdala, as described above. When the amygdala lesions were completed, the monkeys were transferred to a specially designed headholder that permitted unobstructed access to the temporal portion of the head. The temporal muscles on each side were fully retracted, the zygomatic arch was removed, and openings were made on each side of the skull to expose the lateral portion of the temporal lobe. The hippocampus on each side was approached by elevating the occipitotemporal convexity and entering the brain medial to the occipitotemporal sulcus and caudal to the entorhinal cortex. The hippocampus, including dentate gyrus and subicular complex, was removed. The removal was also intended to include most of the parahippocampal gyrus (area TFTH of Bonin and Bailey, 1947) and the posterior half of the entorhinal cortex. The upper surface of the lateral ventricle served as an identifiable dorsal boundary along the entire length of the removal. Care was taken to avoid damaging the anterior portion of the entorhinal cortex, i.e., the region beneath the amygdala and the perirhinal cortex.

The procedure for making the lesions in the $\mathrm{H}^{+}$group (Zola-Morgan and Squire, 1986; Zola-Morgan et al., 1989) was the same as was used for making the hippocampal lesions in the $\mathrm{H}^{+} \mathrm{A}$ group. For all monkeys, the dura, muscle, and skin were sutured following achievement of hemostasis. During postoperative recovery, monkeys were placed in a specially designed incubator for $24-72 \mathrm{hr}$ and were then returned to their home cages.

\section{Behavioral testing}

Monkeys were allowed 6-8 weeks of recovery prior to the start of behavioral testing. All testing was carried out in a Wisconsin General Test Apparatus (Harlow and Bromer, 1938). During 4-6 sessions of pretraining, monkeys learned to obtain food by displacing objects that covered any of 3 food wells located on a stimulus tray in front of the testing chamber. Seven different tasks (described in detail in Zola-Morgan and Squire, 1984, 1985) were administered to all monkeys in the order listed below.

1. Trial-Unique delayed nonmatching to sample. Monkeys first displaced an object covering the central food well to obtain a raisin reward, and an opaque door was lowered to block the monkey's view of the food wells. After $8 \mathrm{sec}$ monkeys saw 2 objects, the original object and a new one, which covered the 2 lateral food wells. They displaced the new object to obtain the raisin. The position of the correct object (left or right) varied on each trial according to a pseudo-random schedule (Gellerman, 1933). Twenty such trials were presented daily with an intertrial interval of $20 \mathrm{sec}$. Each trial used a new pair of objects, selected randomly from a collection of more than 300 junk objects. After reaching the learning criterion of 90 correct choices in 100 trials, monkeys were tested with successively longer delays of $15 \mathrm{sec}, 60 \mathrm{sec}$, and then $10 \mathrm{~min}$ between the sample and choice trials. One hundred trials were given at the 15 and $60 \mathrm{sec}$ delays; 50 trials were given at the $10 \mathrm{~min}$ delay. Twenty trials were given daily for the 15 and $60 \mathrm{sec}$ delays, and 5 trials were given daily for the 10 min delay.

2. Pattern discrimination. Monkeys were next tested on 2 pattern discrimination tasks. For these tasks cues of color, size, and 3 dimen- 


\section{Intended Lesions}

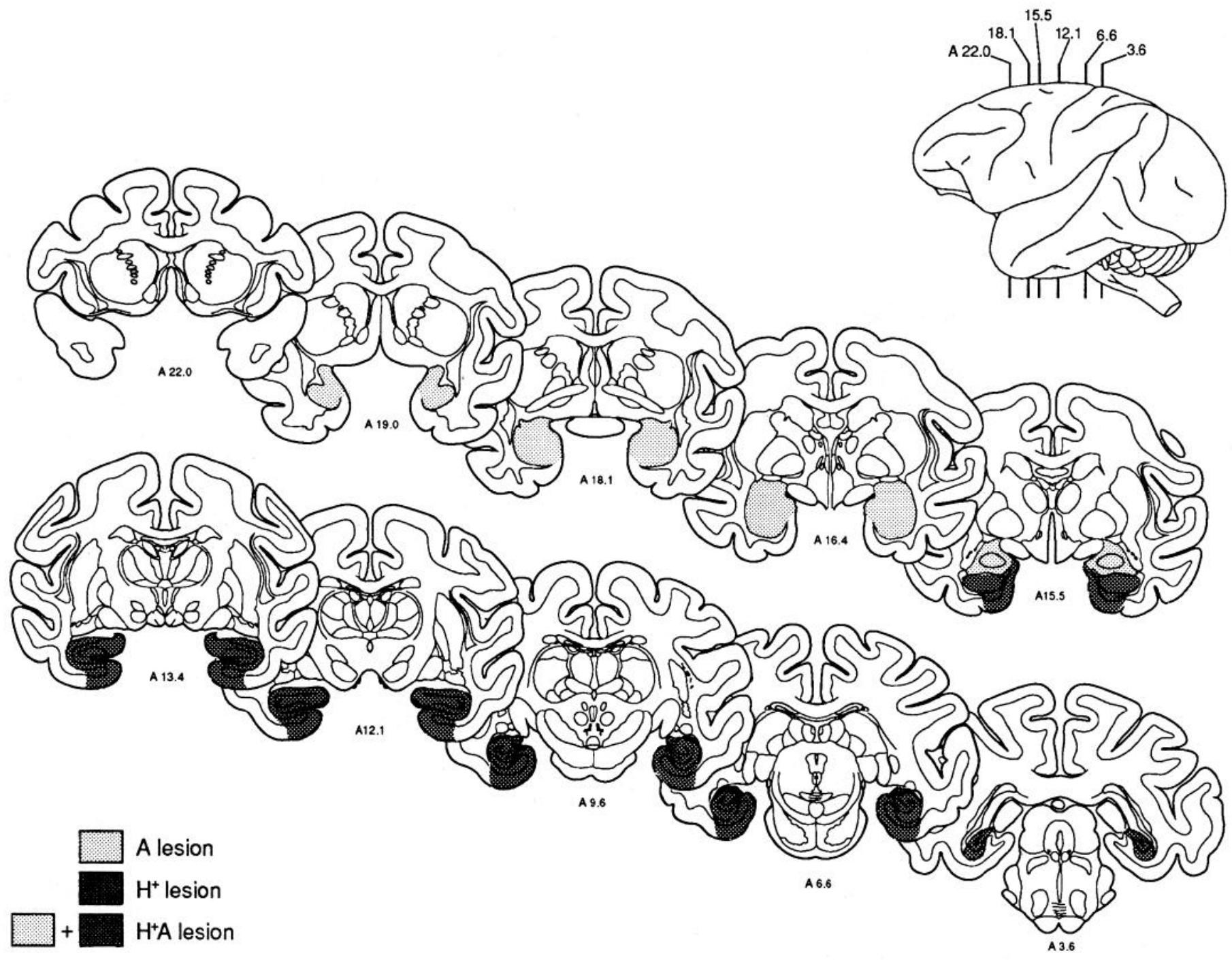

Figure 1. Representative cross sections through the temporal lobes, illustrating the intended lesions in the A group (light stipple), the $\mathrm{H}^{+}$group (dark stipple), and the $\mathrm{H}^{+} \mathrm{A}$ group (light and dark stipple). Numerals beneath the coronal sections indicate the approximate distance (in mm) from the interaural plane and correspond to those on the lateral view. (Atlas drawings based on Szabo and Cowan, 1984.)

sional shape were not available. In the first task, monkeys learned to discriminate a plus sign from a square, and in the second task, they learned to discriminate an $\mathrm{N}$ from a W. A correct choice uncovered a raisin reward, and an incorrect choice uncovered an empty food well. The position of the correct plaque (over the left or right lateral food wells) was determined by a Gellerman sequence. Training continued until animals achieved a learning criterion of at least $90 \%$ correct performance or better on 2 consecutive days. Twenty trials per day were administered for the first task, and 30 trials per day were administered for the second task.

3. Delayed retention of object discriminations. Monkeys learned 4 separate 2-choice object-discrimination tasks. Each discrimination pair consisted of distinctive objects that could be learned by normal monkeys in a single session. Each discrimination task was administered for 2 daily sessions of 20 trials each, with an intertrial interval of $15 \mathrm{sec}$. Following a $2 \mathrm{~d}$ delay, an additional session of 20 trials was given. The correct stimulus object appeared over the left and right food wells in a Gellerman sequence, and a raisin reward was always concealed under the correct object. Between 5-7 d intervened between each of the 4 discrimination problems.

4. Concurrent discrimination learning. Eight pairs of junk objects were used. The pairs were presented in an intermingled fashion during each testing session so that all 8 discriminations had to be learned simulta- neously. Specifically, on each trial one pair of objects was presented over the lateral food wells, and during the course of each daily testing session of 40 trials, every pair was presented 5 times. The intertrial interval was $15 \mathrm{sec}$. The same object of a pair was always correct each time it was presented. The position of the correct object (left or right) was determined by a Gellerman sequence, and a raisin reward was always concealed under the correct object. Testing continued until a learning criterion of 39 correct responses in 40 consecutive trials was achieved during one test session.

5. Delayed response with and without distraction. Testing proceeded in 2 phases, basic training and then testing with delays. Basic training was as follows: With the opaque door in the raised position, 1 of the 2 lateral food wells was baited with a raisin reward while the monkey watched. Both food wells were then covered by identical square black plaques. The opaque screen was then lowered between the monkey and the food wells. After a delay of approximately $8 \mathrm{sec}$, the opaque screen was raised, and the monkey was allowed to choose between the 2 covered food wells. Monkeys were tested for 20 trials a day to a learning criterion of 90 correct responses in 100 consecutive trials. The intertrial interval was 20 sec. Testing on delays (with and without distraction) was accomplished as follows: Monkeys were tested with short $(15 \mathrm{sec})$ and long $(30 \mathrm{sec})$ delays, beginning on the day after criterion was reached on the basic task. Five conditions ( $8 \mathrm{sec}-$ no distraction; $15 \mathrm{sec}-$ no dis- 
traction; $15 \mathrm{sec}-$ distraction; $30 \mathrm{sec}-$ no distraction; $30 \mathrm{sec}-$ distraction) were presented in daily sessions of 25 trials. Each condition occurred randomly 5 times a day. A total of 10 daily sessions was administcred for a total of 50 trials in cach condition. For the 3 nodistraction conditions, testing was the same as in basic training except that the delay could be 8,15 , or $30 \mathrm{sec}$. For the 2 distraction conditions, the plaques and the bait were quickly removed and a distracting event was introduced during the delay interval. The distracting event consisted of the presentation of an irrelevant junk object (once during the $15 \mathrm{sec}$ delays or 3 times during the $30 \mathrm{sec}$ delays), which monkeys could displace to obtain a raisin reward. The same object was used as the distractor throughout testing.

6. Delayed nonmatching to sample retest. Monkeys were retested on delayed nonmatching to sample (see test 1 , above). The average interval between tests 1 and 7 was 21 months. The normal monkeys were not given this retest.

7. Lifesaver motor-skill task. This task was adapted from one described by Davis ct al. (1956). Monkeys learned to obtain an edible Lifesaver candy by maneuvering it a distance of 4 inches along a metal rod and around a right-angle turn for a distance of 1.5 inches. Prior to formal testing, monkeys were first pretrained to retrieve the candy Lifesaver when it was placed directly at the end of the metal rod and could be removed without difficulty. For formal testing, 6 trials a day were given in which the monkey was allowed $30 \mathrm{sec}$ to retrieve the Lifesaver by maneuvering it from the center of the rod, around the bend, and off the end of the rod. If $30 \mathrm{sec}$ elapsed before the monkey obtained the Lifesaver, the opaque door was lowered and the trial was reset with the Lifesaver at the center of the rod. Sessions were given every other day, for a total of 8 sessions. One month after the 8th learning session, monkeys were retested by giving them 2 additional sessions on 2 consecutive days.

\section{Histological evaluation}

After completion of testing, operated monkeys were killed with an overdose of Nembutal and perfused with $0.9 \%$ saline and $10 \%$ buffered formalin. The brains were removed, blocked, dehydrated, and embedded in albumin. Frozen sections were cut in the coronal plane at a thickness of $50 \mu \mathrm{m}$. Every fifth section through the area of the lesion was mounted on a glass slide and stained with thionin.

\section{Results}

\section{Histological findings}

\section{Lesions of the amygdala}

Two of the animals in this group had extensive bilateral damage to the amygdaloid complex with only minor damage to surrounding areas (Fig. 3). In a third animal, the lesion was more posteriorly and medially placed so that there was sparing of the rostral pole of the amygdala bilaterally and of the lateral nucleus at more caudal levels.

Animal A1 had the most complete and selective lesion of the amygdaloid complex (Figs. 2 and 3). The lesion began at the rostral pole of the amygdala but spared the rostrally adjacent perirhinal cortex and the medially adjacent pcriamygdaloid cortex. For much of the rostrocaudal extent of the amygdala, the lesion eliminated approximately three-fourths of its mediolateral extent and removed most of the lateral, basal, and accessory basal nuclei. There was some sparing of the anterior and medial portions of the accessory basal nucleus on the right side. The central nucleus was damaged bilaterally. The lesion closely apposed the laterally adjacent white matler but did not appear to invade it appreciably. Only the surface regions of the amygdala, including the cortical and medial nuclei and the periamygdaloid cortex, remained intact bilaterally. The lesion extended only slightly beneath the amygdala so that there was only minor direct damage to the entorhinal and perirhinal cortices. The damage did extend caudal to the amygdala (more on the left side than on the right), and the anterior pole of the hippocampus and dentate gyrus were bilaterally damaged.
In animal A2, the lesion was similar in size to that of animal A1 but was positioned more ventrally and medially. The amygdaloid damage extended throughout the full rostrocaudal extent of the amygdala and involved most of the lateral, basal, and accessory basal nuclei bilaterally. Structures on the medial surface of the amygdala were spared on the left and were partially damaged on the right. There was some slight sparing of the lateral nucleus on the right side and of the parvicellular portion of the basal nucleus on the left. Caudally, the central nucleus was spared bilaterally. The lesion extended below the amygdala bilaterally, reaching the fundus of the rhinal sulcus and damaging the subjacent perirhinal cortex and the most lateral aspect of the entorhinal cortex. The lesion also extended caudal to the amygdala and damaged the rostral pole of the hippocampus and dentate gyrus bilaterally.

The lesion in the third animal (A3) was placed more caudally and medially than in the other animals. The anterior pole of the amygdala was intact bilaterally (accounting for approximately one-third of its rostrocaudal extent). Throughout the caudal two-thirds of the amygdala, the basal and accessory basal nuclei were damaged bilaterally, but there was some sparing of the lateral nucleus bilaterally. The central nucleus was damaged bilaterally. The lesion did not extend lateral or ventral to the amygdala but did extend caudal to it and bilaterally damaged the rostral pole of the hippocampus and dentate gyrus.

\section{Combined lesions of the hippocampus and amygdala}

The damage in the 3 monkeys in the $\mathrm{H}^{+} \mathrm{A}$ group is illustrated in Figure 4. Animal $\mathrm{H}^{+} \mathrm{A} 1$ had an extensive bilateral lesion of the amygdaloid complex and a fairly complete bilateral removal of the dentate gyrus, hippocampus, and subicular complex. The lesion of the amygdala extended throughout its rostrocaudal extent and was similar in size to that in animals A1 and A2. On the right side, a small portion of the lateral nucleus was spared, but the other deep nuclei, as well as much of the medial surface, were eliminated. On the left side, the deep nuclei were all extensively damaged, and only a thin strip of the medial surface, consisting primarily of periamygdaloid cortex, remained intact. The perirhinal cortex located rostral and ventral to the amygdala was not directly involved by the lesion. The subjacent entorhinal cortex was not directly damaged, though the cells of layer II were nearly completely depopulated through retrograde neuronal degeneration as the result of the elimination of their terminal field in the dentate gyrus. The body of the hippocampus and dentate gyrus were bilaterally eliminated for most of their rostrocaudal extent, though about $2 \mathrm{~mm}$ of these fields was spared caudally. At rostral levels of the hippocampal formation on the right side, there was some sparing of the medial portion of the hippocampus and dentate gyrus. The subicular complex was damaged bilaterally, though at least some of the rostral subiculum and presubiculum was spared. There was little or no direct involvement of the entorhinal cortex by the lesion. However, as noted above, layer II was nearly entirely eliminated through retrograde cell degeneration. Anterior portions of the parahippocampal gyrus were damaged, but the caudal two-thirds of areas TF and TH were spared.

In the second animal $\left(\mathrm{H}^{+} \mathrm{A} 2\right)$, the lesion also extended throughout much of the rostrocaudal extent of the amygdala. The lesion was larger on the left side than on the right, and on the left there were no identifiable amygdaloid nuclei spared. All fields of the hippocampal formation on the left side were nearly completely eliminated by the lesion. Only the caudal-most 2 

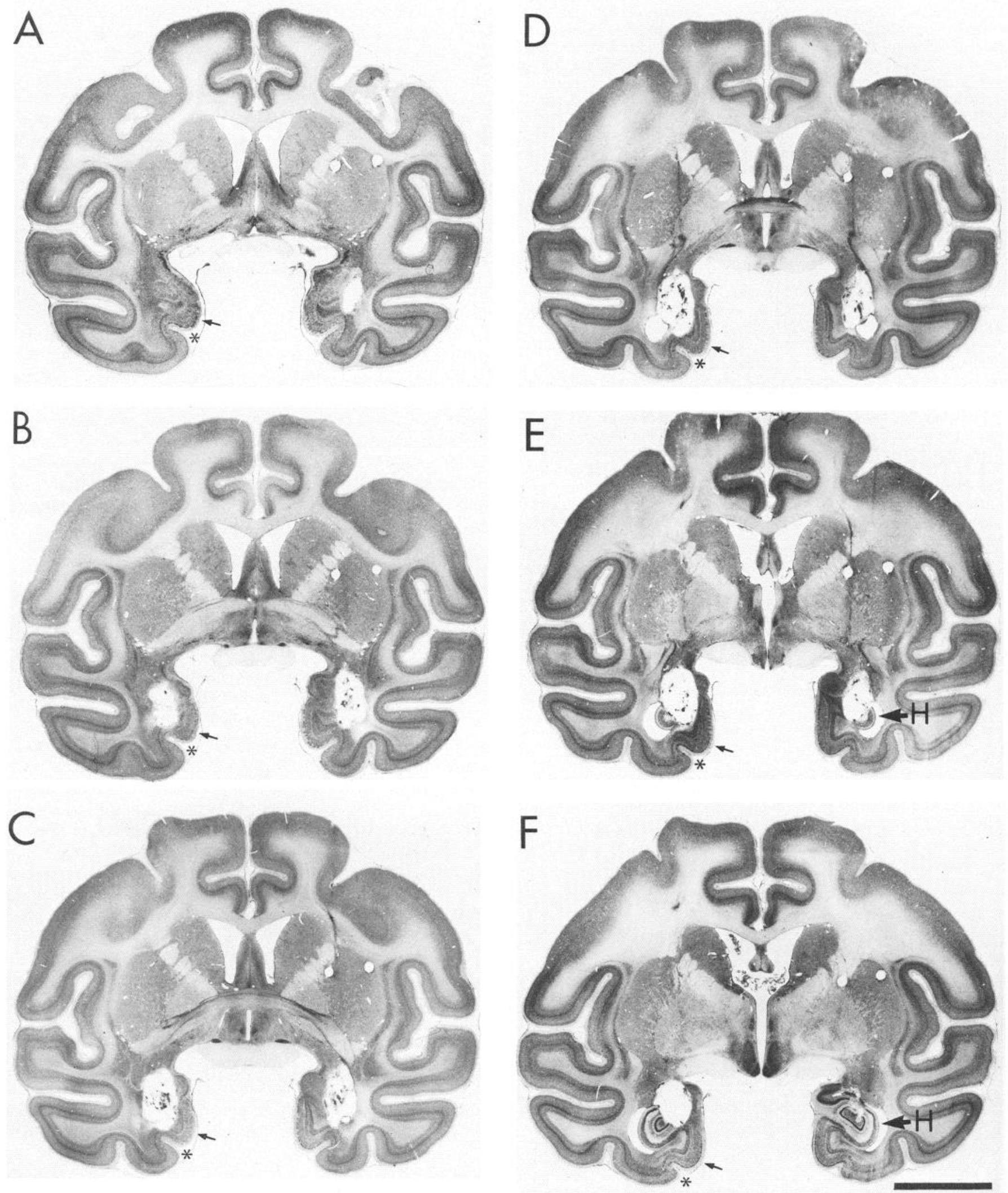

Figure 2. Representative Nissl-stained coronal sections through the amygdaloid complex in animal A1. Sections are arranged from rostral $(A)$ to caudal $(F)$. The lesion involves much of the rostrocaudal and mediolateral extent of the amygdala. Only superficial regions, such as the periamygdaloid cortex, are preserved on both sides, and a small amount of the accessory basal nucleus is also preserved on the right side. The lesion extends into the rostral pole of the hippocampus and dentate gyrus $(H)$. The arrow on the left side of each panel indicates the entorhinal cortex that was not damaged by the lesion, and the asterisk marks the rhinal sulcus. Scale bar, $10 \mathrm{~mm}$. 
A1
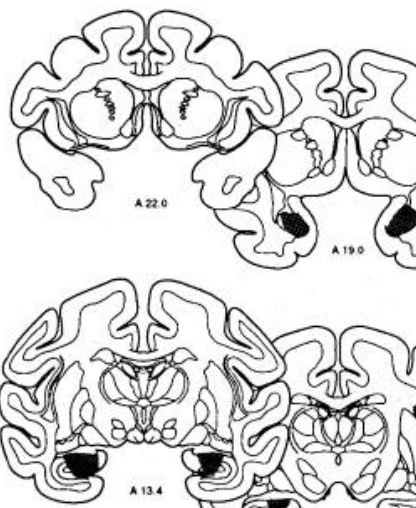<smiles>C1CCCCC1</smiles>
.... .
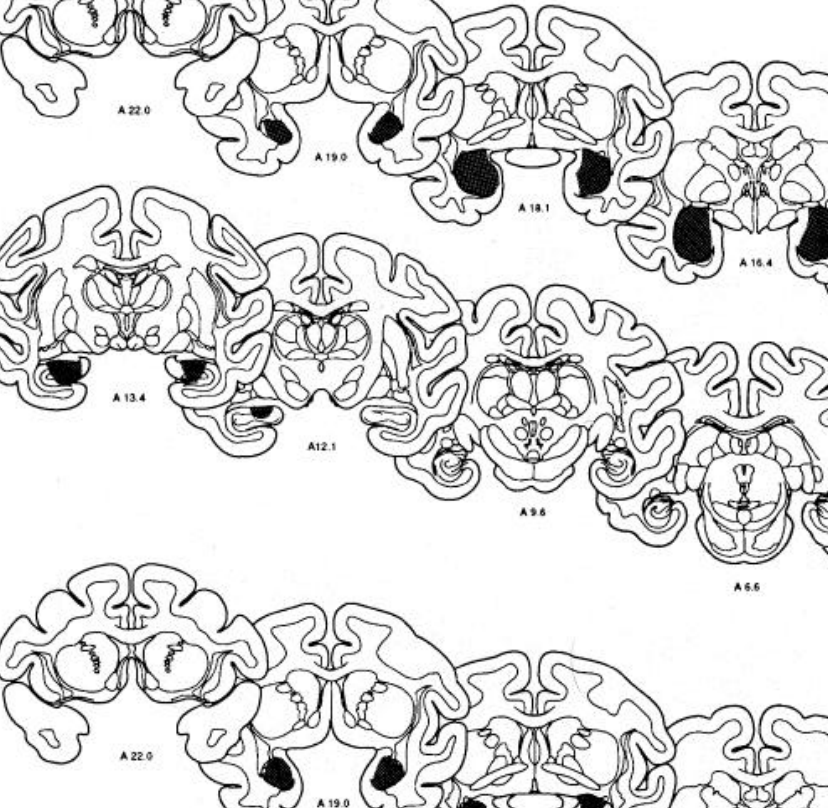

A 6.6

A2
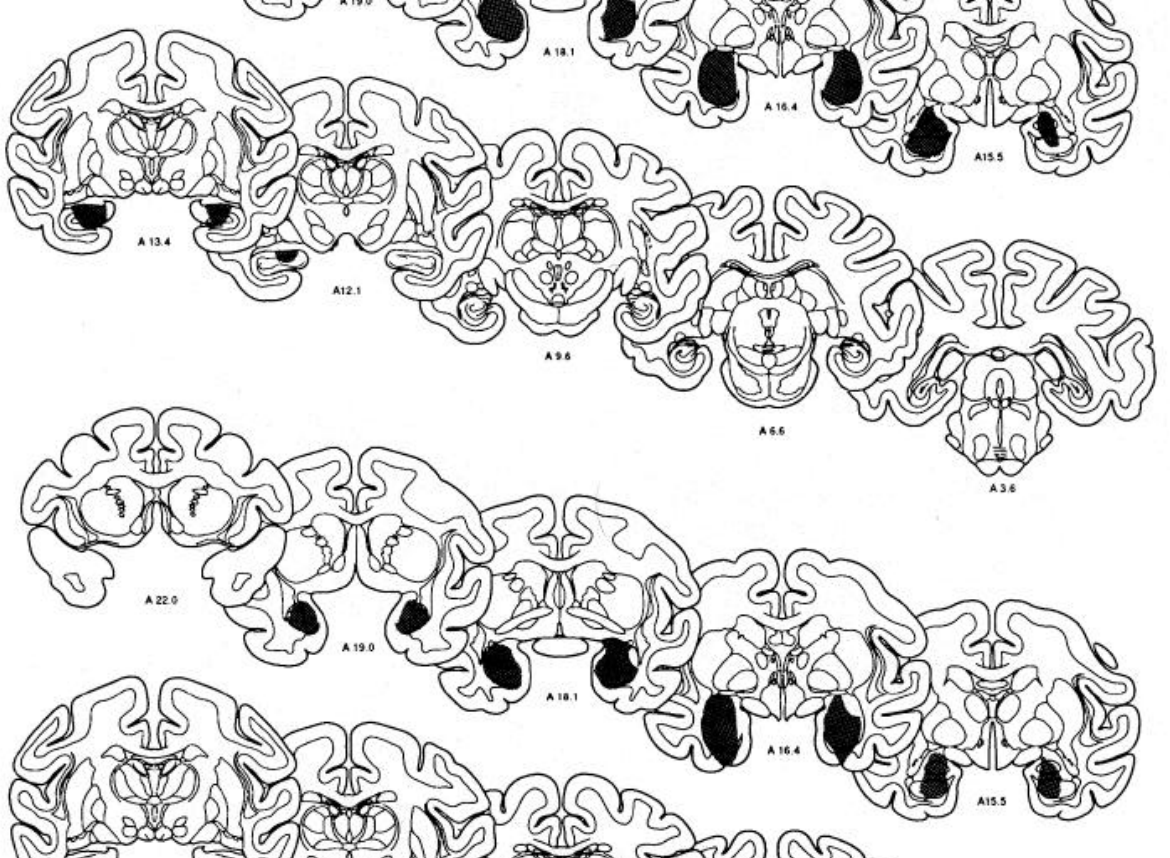

A3

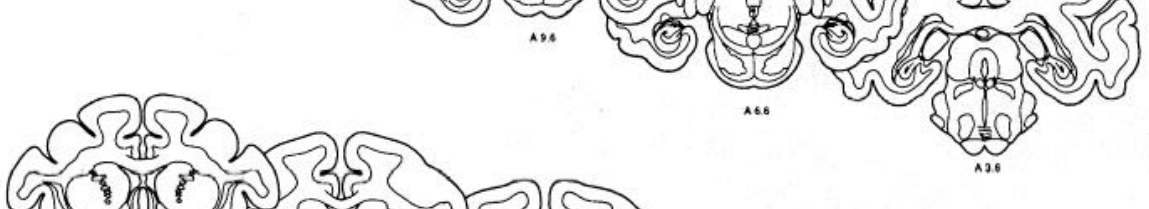

स्री
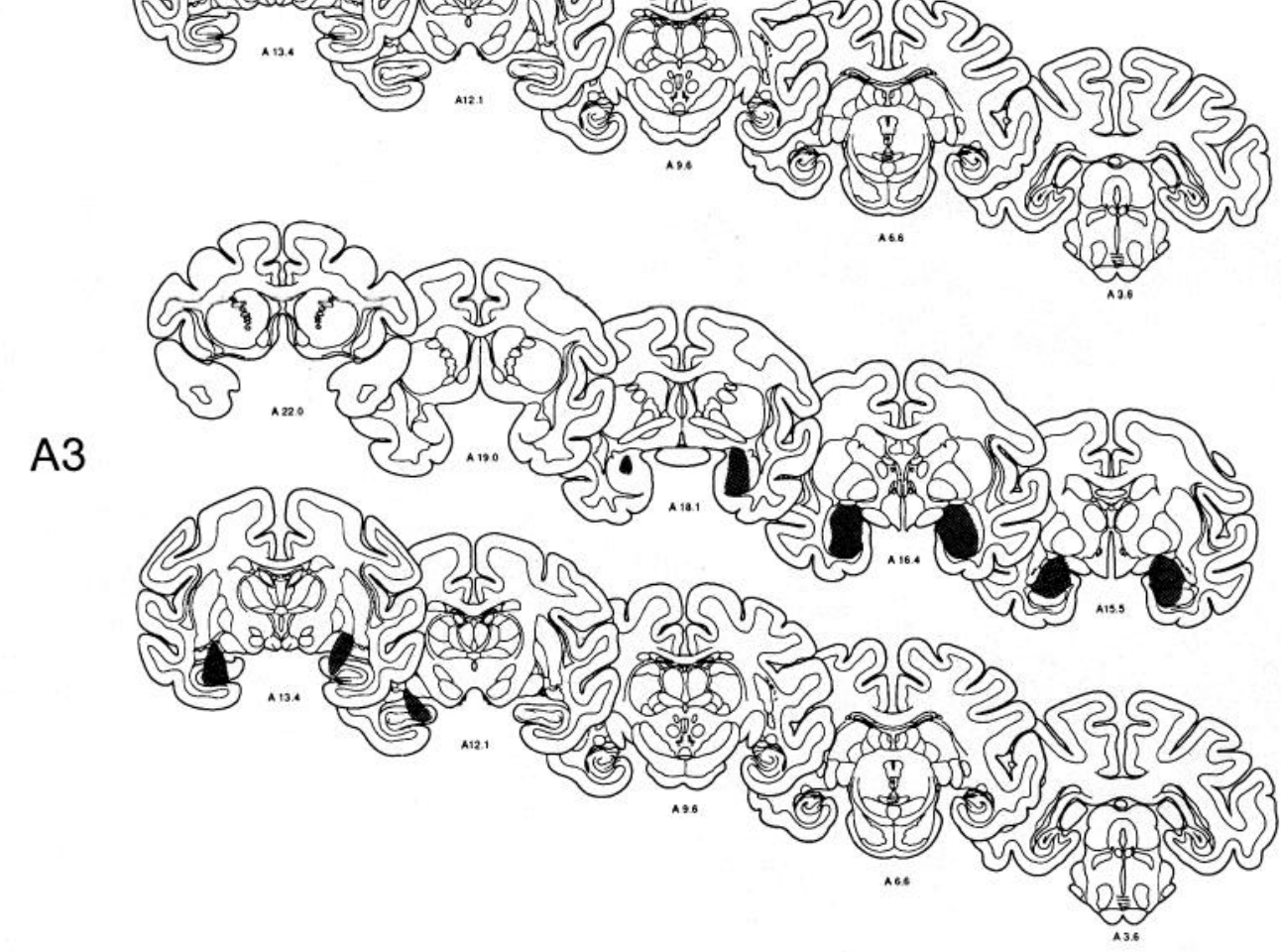

Figure 3. Representative coronal sections through the temporal lobes showing the extent of damage (stippled region) in the 3 monkeys with lesions of the amygdaloid complex $(A)$. The coronal sections correspond to those in Figure 1.

$\mathrm{mm}$ of the hippocampus and dentate gyrus were preserved. An infarct located lateral and ventral to the amygdala on the left side resulted in damage to the inferotemporal, perirhinal, and entorhinal cortices, as well as the white matter separating these regions. This infarct continued caudally and damaged much of the entorhinal and perirhinal cortex on the left side. On the right side, the lesion was focused in the middle of the amygdala and eliminated all of the basal nucleus and much of the accessory basal nucleus. At caudal levels, there was substantial sparing of the lateral and accessory basal nuclei and the perirhinal cortex remained largely intact. The anterior half of the hippocampal formation on the right side also remained intact. At a midros- 


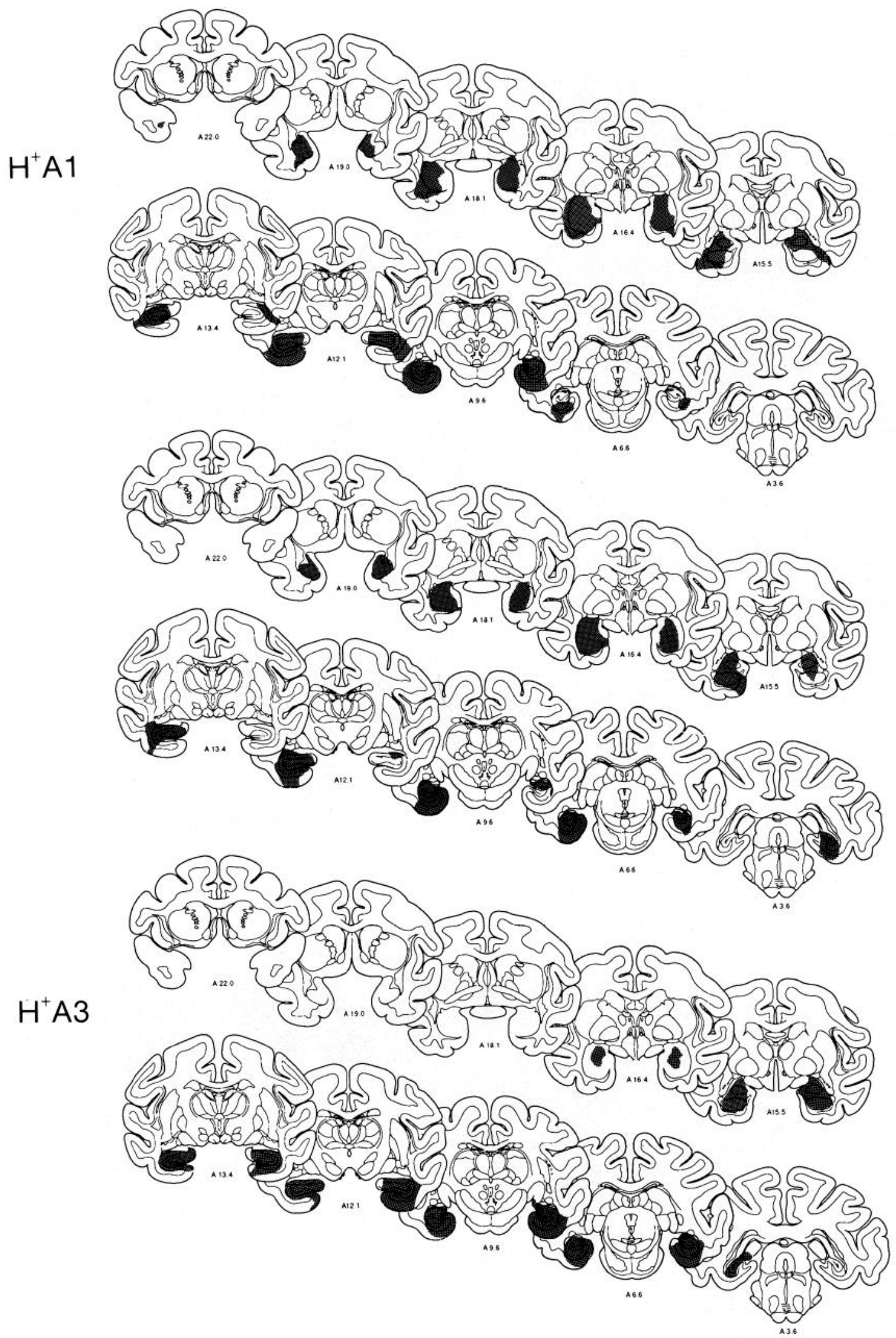

Figure 4. Representative coronal sections through the temporal lobes showing the extent of damage (stippled region) in the 3 monkeys with conjoint lesions of the hippocampal formation and the amygdala $\left(H^{+} A\right)$. The coronal sections correspond to those in Figure 1. 


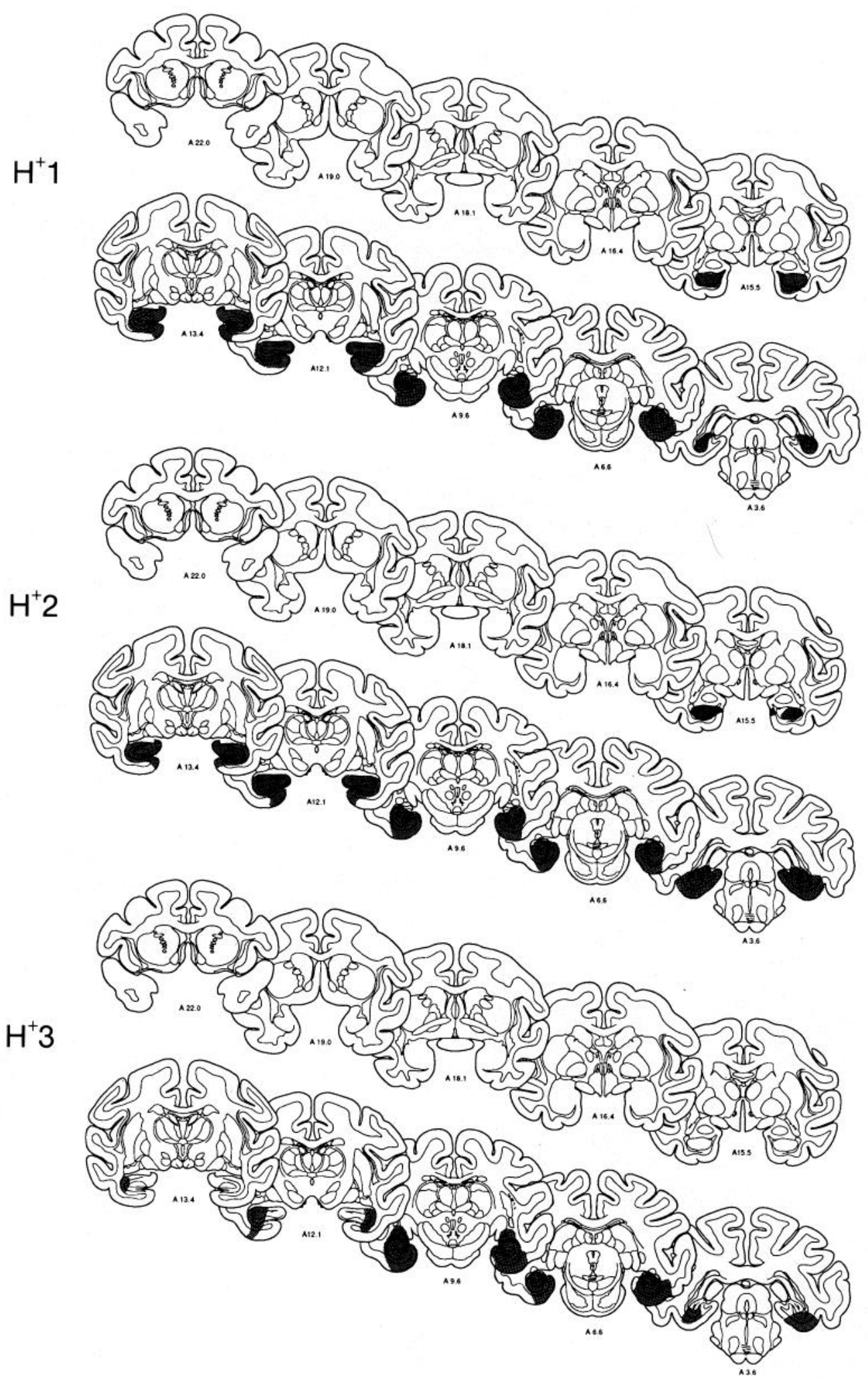

Figure 5. Representative coronal sections thorough the temporal lobes showing the extent of damage (stippled region) in the 3 monkeys with lesions of the hippocampal formation $\left(H^{+}\right)$. The coronal sections correspond to those in Figure 1. trocaudal level, the dorsal aspect of the hippocampus and dentate gyrus were directly involved by the lesion. The fornix was also transected at this level. The caudal third of the hippocampus and dentate gyrus were directly eliminated by the suction ablation. In summary, in this animal the amygdala was damaged bilaterally, but the lesion was complicated by the fact that while the hippocampal formation on the left side was almost completely eliminated, the rostral half of the right hippocampus was largely intact. However, because the fornix was transected on the right side and the caudal half of the hippocampus and dentate gyrus were directly damaged, the hippocampal formation was likely to have been substantially compromised bilaterally. 
Table 1. Delayed nonmatching to sample

\begin{tabular}{|c|c|c|c|c|c|}
\hline \multirow[b]{2}{*}{ Group } & \multirow[b]{2}{*}{$\begin{array}{l}\text { Trials to } \\
\text { criterion }\end{array}$} & \multicolumn{4}{|c|}{ Delays } \\
\hline & & $8 \mathrm{sec}$ & $15 \mathrm{sec}$ & $60 \mathrm{sec}$ & $\begin{array}{l}10 \\
\min \end{array}$ \\
\hline \multicolumn{6}{|l|}{$\mathbf{N}$} \\
\hline 1 & 120 & 91 & 98 & 91 & 82 \\
\hline 2 & 180 & 92 & 92 & 90 & 85 \\
\hline 3 & 140 & 90 & 86 & 83 & 74 \\
\hline Mean & 147 & 91 & 92 & 88 & 80 \\
\hline \multicolumn{6}{|l|}{ A } \\
\hline 1 & 180 & 92 & 78 & 90 & 80 \\
\hline 2 & 180 & 91 & 92 & 89 & 72 \\
\hline 3 & 280 & 90 & 84 & 87 & 80 \\
\hline Mean & 213 & 91 & 85 & 89 & 77 \\
\hline \multicolumn{6}{|l|}{$\mathrm{H}^{+} \mathrm{A}$} \\
\hline 1 & 1140 & 90 & 83 & 75 & 72 \\
\hline 2 & 740 & 90 & 89 & 55 & 62 \\
\hline 3 & 240 & 93 & 87 & 83 & 67 \\
\hline Mean & 707 & 91 & 86 & 71 & 67 \\
\hline \multicolumn{6}{|l|}{$\mathrm{H}^{+}$} \\
\hline 1 & 260 & 91 & 85 & 78 & 60 \\
\hline 2 & 520 & 92 & 90 & 78 & 64 \\
\hline 3 & 840 & 91 & 88 & 91 & 68 \\
\hline Mean & 540 & 91 & 88 & 82 & 64 \\
\hline
\end{tabular}

$\mathrm{N}$, normal monkeys; $\mathrm{A}$, monkeys with circumscribed lesions of the amygdala; $\mathrm{H}^{+} \mathrm{A}$, monkeys with circumscribed lesions of the amygdala plus lesions of the hippocampal formation; $\mathrm{H}^{+}$, monkeys with lesions of the hippocampal formation.
In the third animal $\left(\mathrm{H}^{+} \mathrm{A} 3\right)$, the lesion involved the caudal third of the amygdaloid complex, and at this level only the basal nucleus was completely eliminated. The subjacent entorhinal and perirhinal cortices were not involved in the lesion. At the rostral pole of the hippocampal formation, the entorhinal cortex was eliminated on the right side but was preserved on the left. All other fields of the hippocampal formation (aside from a small remnant of medial or uncal hippocampus) were entirely removed bilaterally. The removal was complete throughout much of the rostrocaudal extent of the hippocampal formation. Approximately $0.5 \mathrm{~mm}$ of the caudal hippocampus and dentate gyrus were spared on the left side and approximately $1.5 \mathrm{~mm}$ on the right side. The perirhinal cortex was largely uninvolved in the lesion. The parahippocampal gyrus was damaged bilaterally.

\section{Lesions of the hippocampus}

The lesions in these animals were described previously (ZolaMorgan et al., 1989). Here, we summarize the damage (Fig. 5). Monkeys $\mathrm{II}^{+} 1$ and $\mathrm{II}^{+} 2$ sustained complete bilateral hippocampal removals. The rostral third of the entorhinal cortex was intact in both cases, but layer II was eliminated through retrograde degeneration. The posterior portion of the entorhinal cortex was directly damaged, and the lesion extended laterally to encompass the parahippocampal gyrus bilaterally. In $\mathrm{H}^{+} 1$ the amygdaloid complex was intact, in $\mathrm{H}^{+} 2$ there was only very minor damage to the caudal pole of the amygdala. In both animals, the fimbria were shrunken and gliotic. Monkey $\mathrm{H}^{+} 3$ had a smaller lesion involving about half of the hippocampal

Table 2. Performance of tasks sensitive to amnesia

\begin{tabular}{llllll} 
& $\begin{array}{l}\text { Delayed } \\
\text { nonmatching }\end{array}$ & $\begin{array}{l}\text { Object } \\
\text { retention }\end{array}$ & $\begin{array}{l}\text { Concurrent } \\
\text { discrimination }\end{array}$ & $\begin{array}{l}\text { Delayed } \\
\text { response }\end{array}$ & $\begin{array}{l}\text { Delayed } \\
\text { nonmatch- } \\
\text { ing retest }\end{array}$ \\
\hline $\mathrm{N}$ & & & & & - \\
1 & 90 & 83 & 440 & 80 & - \\
2 & 89 & 87 & 480 & 75 & - \\
3 & 81 & 84 & 680 & 64 & - \\
Mean & 87 & 85 & 533 & 73 & 92 \\
$\mathrm{~A}$ & & & & & 84 \\
1 & 83 & 88 & 360 & 72 & 89 \\
2 & 84 & 84 & 520 & 77 & 88 \\
3 & 87 & 82 & 380 & 78 & 75 \\
Mean & 85 & 85 & 420 & 76 & 79 \\
$\mathrm{H}^{+} \mathrm{A}$ & & & & & 77 \\
1 & 77 & 75 & 720 & 69 & \\
2 & 69 & 66 & 720 & 63 & 76 \\
3 & 79 & 76 & 520 & 58 & 82 \\
Mean & 75 & 72 & 653 & 63 & 81 \\
$\mathrm{H}^{+}$ & & & & & \\
1 & 74 & 75 & 760 & 53 & 63 \\
2 & 77 & 72 & 720 & 63 & \\
3 & 82 & 80 & 880 & 62 & \\
Mean & 78 & 76 & 787 & 59 & \\
\hline
\end{tabular}

The score for the delayed nonmatching task and for the retest of the delayed nonmatching task is the percent correct score averaged across 3 delays $(15 \mathrm{sec}, 60 \mathrm{sec}$, and $10 \mathrm{~min})$. The score for the object-retention task is the percent correct score averaged across 3 test days. The score for concurrent discrimination is the number of trials required to reach the learning criterion. The score for the delayed response task is the percent correct score averaged across 2 delays (15 and $30 \mathrm{sec}$ ) and 2 distraction conditions (with and without). N, normal monkeys; A, monkeys with circumscribed lesions of the amygdala; $\mathrm{H}^{+} \mathrm{A}$, monkeys with circumscribed lesions of the amygdala plus lesions of the hippocampal formation; $\mathrm{H}^{+}$, monkeys with lesions of the hippocampal formation. 

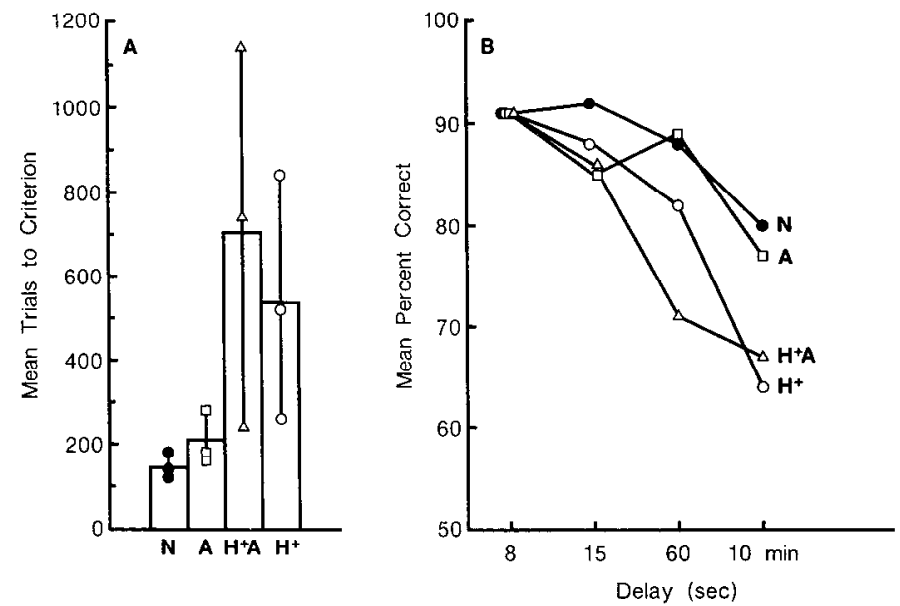

Figure 6. Performance on the delayed nonmatching to sample task by normal monkeys $(N)$, by monkeys with lesions of the hippocampal formation $\left(H^{+}\right)$or the amygdala $(A)$, and by monkeys with conjoint lesions of the hippocampal formation and the amygdala $\left(H^{+} A\right)$. $A$, Initial learning of the task with a delay of $8 \mathrm{sec}$. Symbols show trials to criterion for individual animals. $B$, Performance across delays for the same groups.

formation bilaterally. Approximately the anterior $30 \%$ of the hippocampal formation and the posterior $20 \%$ were uninvolved by the ablation. The entorhinal cortex was intact, but there was partial loss of layer II cells. There was also bilateral damage of the parahippocampal gyrus, but this was not as extensive as in the other 2 monkeys. The amygdaloid complex was not involved by the lesion, but at caudal levels the ablation exceeded the dorsal limit of the ventricle and directly damaged the tail of the caudate nucleus, the lateral geniculate nucleus, and the optic radiations bilaterally.

\section{Summary of histological findings}

In the A group, 2 animals had nearly complete bilateral lesions of the amygdala with minimal damage to the adjacent perirhinal and entorhinal cortices and the laterally adjacent temporal neocortex. Spared amygdaloid tissue consisted primarily of superficial regions, including the cortical and medial nuclei, the periamygdaloid cortex, and the amygdalohippocampal area. In the third animal the lesion was somewhat smaller and spared much of the anterior third of the amygdala. In all cases, damage extended into the rostral pole of the hippocampal formation. In the $\mathrm{H}^{+} \mathrm{A}$ group, 2 animals had selective and extensive bilateral damage of the amygdala much like that in the A group. One of these animals had nearly a complete bilateral removal of the hippocampus and dentate gyrus with only a small caudal portion of these areas spared. The second animal had sparing of the rostral half of the hippocampus and dentate gyrus on one side, but the posterior half of these fields was removed and the fornix was transected. The third animal had a complete bilateral removal of the hippocampus and dentate gyrus but a relatively limited bilateral lesion of the posterior third of the amygdala. In the $\mathrm{H}^{+}$group, 2 animals had nearly complete bilateral removals of the hippocampal formation, while the third animal had bilateral damage confined to the midportion of the hippocampus.

\section{Behavioral findings}

Although the analysis of the behavioral data focuses on group scores, it should be noted that the average scores for each group

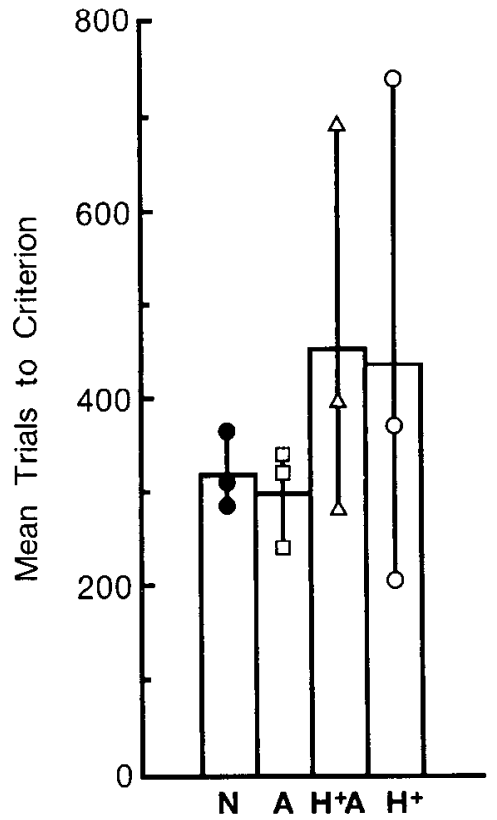

Figure 7. Average score on 2 pattern-discrimination tasks by normal monkeys $(N)$, by monkeys with lesions of the hippocampal formation $\left(H^{+}\right)$or the amygdala $(A)$, and by monkeys with conjoint lesions of the hippocampus and the amygdala $\left(H^{+} A\right)$. Symbols show scores for individual monkeys.

on the tasks sensitive to amnesia are not appreciably changed by excluding the 2 animals $\left(\mathrm{A} 3, \mathrm{H}^{+} \mathrm{A} 3\right.$ ) whose amygdala damage was incomplete (Tables 1,2 ). Similarly, the average scores for each group are not noticeably changed by excluding the 2 animals with incomplete damage to the hippocampal formation $\left(\mathrm{H}^{+} \mathrm{A} 2, \mathrm{H}^{+} 3\right)$.

\section{Delayed nonmatching to sample}

The 4 groups were only marginally different in their ability to learn the basic task with a delay of $8 \sec (F[3,8]=2.9, p=0.10)$. Figure $6 \mathrm{~A}$ shows that the normal group and the $\mathrm{A}$ group required a mean of only 147 trials and 213 trials, respectively, to reach learning criterion on the basic task $(t[4]=1.7, p>0.10)$. The $\mathrm{H}^{+}$group required a mean of 540 trials, and the $\mathrm{H}^{+} \mathrm{A}$ group required a mean of 707 trials $\left(\mathrm{N}\right.$ vs $\mathrm{H}^{+}: t[4]=2.3, p<0.07 ; \mathrm{N}$ vs $\mathrm{H}^{+} \mathrm{A}: t[4]=2.1, p<0.08 ; \mathrm{A}$ vs $\mathrm{H}^{+}$and $\mathrm{A}$ vs $\mathrm{H}^{+} \mathrm{A}: t \mathrm{~s}<1.9$, $p \mathrm{~s}>0.10$ ). The $\mathrm{H}^{+} \mathrm{A}$ group was no more impaired than the $\mathrm{H}^{+}$ group $(t[4]=0.5, p>0.10)$.

Figure $6 B$ shows performance as the delay was increased from $8 \mathrm{sec}$ to $10 \mathrm{~min}$, and Tables 1 and 2 show individual scores for this task. An analysis of variance involving all 4 groups and the 3 longest delays ( $15 \mathrm{sec}, 60 \mathrm{sec}$, and $10 \mathrm{~min}$ ) revealed a significant effect of group $(F[3,8]=4.8, p<0.05)$, delay $(F[2,16]=22.5$, $p<0.001)$, and a group $\times$ delay interaction that fell just short of significance $(F[6,16]=2.3, p=0.08)$. Separate comparisons based on each group's score across these 3 delays revealed that the $\mathrm{H}^{+}$group and the $\mathrm{H}^{+} \mathrm{A}$ group were impaired relative to both the normal group and the A group (all $t \mathrm{~s}>2.7, p \mathrm{~s}<0.05$ ). The $\mathrm{H}^{+}$and $\mathrm{H}^{+} \mathrm{A}$ groups were not distinguishable from each other $(t[4]=0.8, p>0.10)$, and the A group performed normally $(t[4]=1.0, p>0.10)$

\section{Pattern discrimination}

The 2 pattern-discrimination problems proved to be equally difficult. Accordingly, for each monkey, the number of trials 


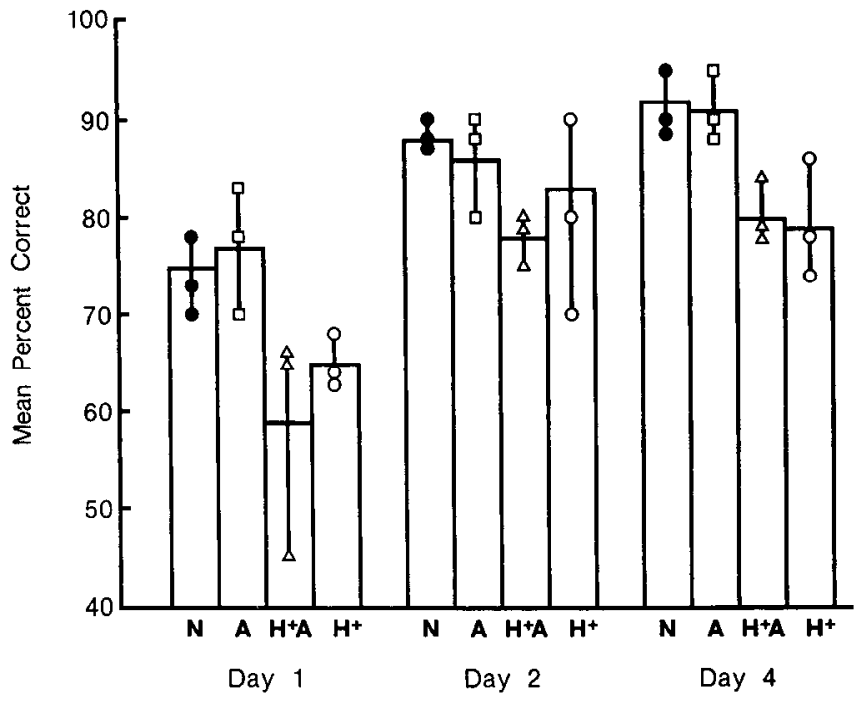

Figure 8. Average daily performance on 4 object-discrimination tasks by normal monkeys $(N)$, by monkeys with lesions of the hippocampal formation $\left(H^{+}\right)$or the amygdala $(A)$, and by monkeys with conjoint lesions of the hippocampal formation and the amygdala $\left(H^{+} A\right)$. Symbols show scores for individual monkeys.

required to learn the first problem and the number of trials required to learn the second problem were averaged together (Fig. 7). None of the operated groups differed from normal monkeys in terms of the number of trials required to learn the pattern discriminations (all $p s>0.10$ ).

In a previous study (Zola-Morgan and Squire, 1984), monkeys with conjoint hippocampal-amygdala lesions (here termed $\mathrm{H}^{+} \mathrm{A}^{+}$) also performed well on these same 2 pattern-discrimination tasks but performed poorly on the first few trials of each testing day. In another study, which involved 8 monkeys with lesions of the hippocampal formation, including the $3 \mathrm{H}^{+}$monkeys of the present study (Zola-Morgan and Squire, 1986), performance was also poor on the first few trials of these same pattern-discrimination tasks. It has been suggested that this impairment, which could always be observed during the first 5 trials of each testing day, reflects a component of the task that is not skilllike (see Zola-Morgan and Squire, 1984). Accordingly, in the present study we analyzed separately the scores for the first 5 trials of each test day and the scores for the remaining trials of each test day.

The 4 groups differed in their performance on the first 5 trials of each test day $(F[3,8]=50.8, p<0.001)$. Mean percent correct during the first 5 trials of all testing sessions was $\mathrm{N}=77 \%$, $\mathrm{A}$ $=74 \%, \mathrm{H}^{+}=53 \%, \mathrm{H}^{+} \mathrm{A}=55 \%$. Separate comparison between groups showed that monkeys with $\mathrm{A}$ lesions performed normally $\left(\mathrm{N}\right.$ vs $\mathrm{A}: t[4]=0.80, p>0.10$ ). Monkeys with $\mathrm{H}^{+}$lesions and monkeys with $\mathrm{H}^{+} \mathrm{A}$ lesions were impaired relative to the performance of normal monkeys ( $\mathrm{N}$ vs $\mathrm{H}^{+}: p<0.001$; $\mathrm{N}$ vs $\mathrm{H}^{+} \mathrm{A}$ : $p<0.001)$ and also relative to the performance of monkeys in the A group ( $p$ s $<0.05$ ). Monkeys with $\mathrm{H}^{+}$lesions and $\mathrm{H}^{+} \mathrm{A}$ lesions obtained similar scores $(p>0.10)$. During the remaining trials of each test day, all groups performed similarly $(\mathrm{N}=69 \%$, $\mathrm{A}=73 \%, \mathrm{H}^{+}=67 \%, \mathrm{H}^{+} \mathrm{A}=67 \%$ ). These findings support the suggestion that performance at the beginning of each test day during pattern-discrimination learning depends on a kind of memory that is sensitive to amnesia (Zola-Morgan and Squire, 1984). In summary, all the operated groups performed normally

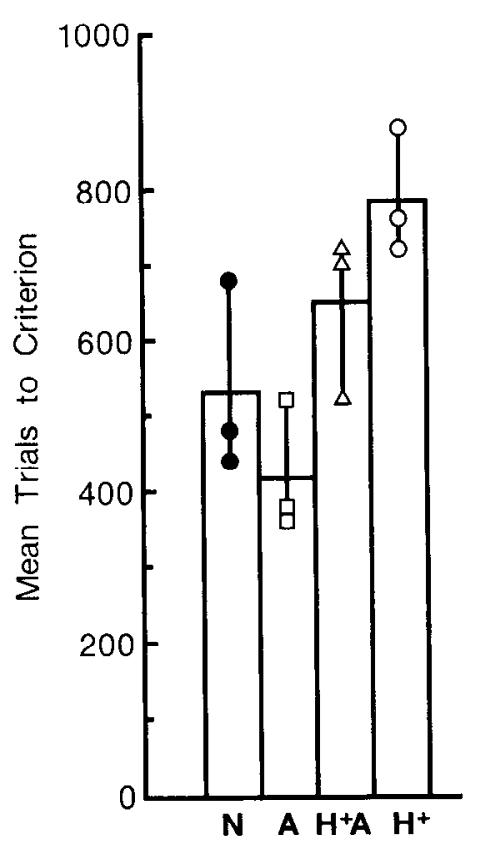

Figure 9. Performance on the 8-pair concurrent task by normal monkeys $(N)$, by monkeys with lesions of the hippocampal formation $\left(H^{+}\right)$ or the amygdala $(A)$, and by monkeys with conjoint lesions of the hippocampal formation and the amygdala $\left(H^{+} A\right)$. Symbols show scores for individual monkeys.

overall on the 2 pattern-discrimination tasks, but the $\mathrm{H}^{+}$and the $\mathrm{H}^{+} \mathrm{A}$ groups were significantly and comparably impaired on the first few trials of each test day.

\section{Delayed retention of object discriminations}

The data for all 4 discriminations were averaged together, and the mean percent correct score was calculated for each day of testing (Fig. 8). A 2-way analysis of variance involving all 4 groups revealed an overall group effect $(F[3,8]=8.1, p<0.01)$, an effect across days $(F[2,16]=46.3, p<0.001)$, and no group $x$ day interaction $(F[6,16]=1.0)$. Separate comparisons between groups, with their scores averaged across the 3 days (Table 2 ), showed that the monkeys with A lesions performed normally ( $\mathrm{N}$ vs $\mathrm{A}: t[4]=0.0$ ). The $\mathrm{H}^{+}$and $\mathrm{H}^{+} \mathrm{A}$ groups were impaired relative to both the normal group $(p s<0.05)$ and the A group ( $p$ s $<0.05$ ). The $\mathrm{H}^{+}$and $\mathrm{H}^{+} \mathrm{A}$ groups performed similarly ( $t$ [4] $=0.85, p>0.50$ ).

Another way to describe these data is to note that all monkeys were eventually able to achieve a run of 9 out of 10 correct trials by the end of Day 2 . The normal group and the A group required a median of 9 and 10 trials, respectively, to learn the 4 tasks (medians are used here to permit direct comparison with the findings reported in Zola-Morgan and Squire, 1985, and in ZolaMorgan et al., 1989), $\mathrm{H}^{+}$monkeys required 20 trials, and $\mathrm{H}^{+} \mathrm{A}$ monkeys required 21 trials. By this measure, both the $\mathrm{H}^{+}$group and the $\mathrm{H}^{+} \mathrm{A}$ group performed worse than the $\mathrm{N}$ and $\mathrm{A}$ groups $(t \mathrm{~s}>2.6, p \mathrm{~s}<0.06)$. In addition, having achieved a high level of performance by the end of Day 2, both the $\mathrm{H}^{+}$and the $\mathrm{H}^{+} \mathrm{A}$ animals performed worse on Day 4 than either the $\mathrm{N}$ or the $\mathrm{A}$ groups (mean percent correct: $\mathrm{N}=92, \mathrm{~A}=91, \mathrm{H}^{+} \mathrm{A}=80, \mathrm{H}^{+}$ $=79 ; t \mathrm{~s}>2.9, p \mathrm{~s}<0.05)$. In summary, the $\mathrm{H}^{+}$and the $\mathrm{H}^{+} \mathrm{A}$ groups were comparably impaired on the object-discrimination task, but the A group performed normally. 

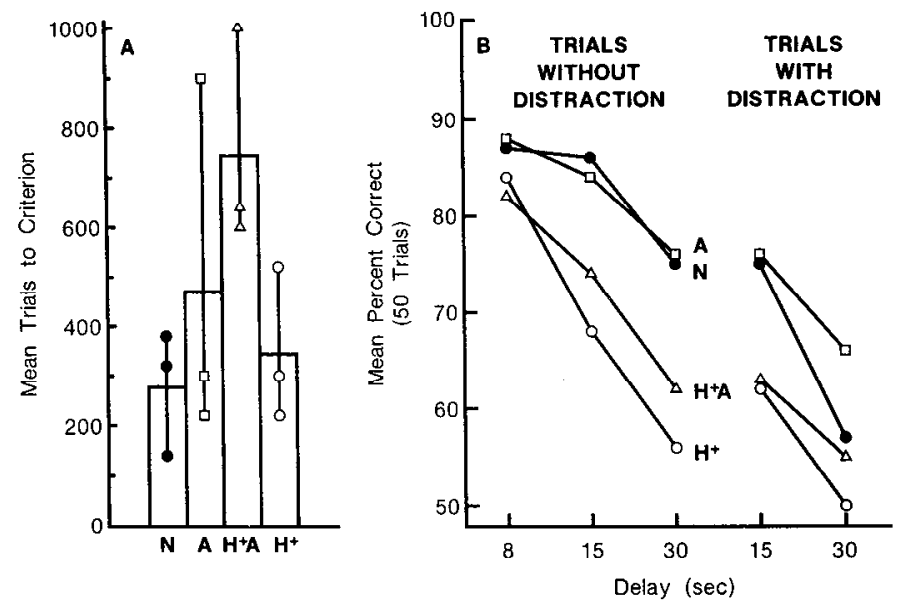

Figure 10. Delayed response performance by normal monkeys $(N)$, by monkeys with lesions of the hippocampal formation $\left(\mathrm{H}^{+}\right)$or the amygdala $(A)$, and by monkeys with conjoint lesions of the hippocampal formation and the amygdala $\left(H^{+} A\right)$. $A$, Initial learning of the task with a delay of $8 \mathrm{sec}$. Symbols show trials to criterion for individual animals. $B$, Performance across delays by normal monkeys and by monkeys in the 3 operated groups. For half of the 15 and $30 \mathrm{sec}$ delays, a distraction task was introduced during the delay.

\section{Concurrent discrimination}

Scores for each group are presented in Figure 9 (mean trials to criterion: $\mathrm{N}=533, \mathrm{~A}=420, \mathrm{H}^{+}=787, \mathrm{H}^{+} \mathrm{A}=653$ ). Individual scores appear in Table 2 . An analysis of variance revealed a significant group effect $(F[3,8]=6.7, p<0.05)$. Further comparisons between groups showed that the monkeys with A lesions performed similarly to normal animals $(t[4]=1.3, p>$ $0.10)$. Monkeys with $\mathrm{H}^{+}$lesions were impaired relative to both the $\mathrm{N}$ and $\mathrm{A}$ groups $(t \mathrm{~s}>2.8, p \mathrm{~s}<0.05)$. The comparison between the $\mathrm{H}^{+} \mathrm{A}$ group and the normal group did not reach statistical significance $(p>0.10)$; however, like the $\mathrm{H}^{+}$group, the $\mathrm{H}^{+} \mathrm{A}$ group performed significantly worse than the A group $(p<0.05)$. Monkeys with $\mathrm{H}^{+} \mathrm{A}$ lesions performed similarly to the $\mathrm{H}^{+}$monkeys $(p>0.10)$.

\section{Delayed response with and without distraction}

Figure $10 A$ shows the number of trials required to learn the basic task at a delay of $8 \mathrm{sec}$ (means: $\mathrm{N}=280$ trials, $\mathrm{A}=473$ trials, $\mathrm{H}^{+}=347$ trials, $\mathrm{H}^{+} \mathrm{A}=747$ trials). Separate comparisons showed that the $\mathrm{H}^{+} \mathrm{A}$ group performed more poorly than the $\mathrm{N}$ group $(t[4]=3.2, p<0.05)$ and marginally more poorly than the $\mathrm{H}^{+}$group $(t[4]=2.6, p<0.06)$. None of the other comparisons were significant $(p s>0.01)$.

Figure $10 B$ shows the effects of increasing the delay interval with and without a distracting event interposed during the delays. A 3-way analysis of variance [4 groups, 2 conditions (distraction and no distraction), and 2 delays (15 and $30 \mathrm{sec}$ )] revealed significant effects of group $(F[3,6]=4.9, p<0.05)$, condition $(F[1,6]=190.4, p<0.01)$, and delay $(F[1,6]=133.9$, $p<0.01)$. There were no significant interactions $(F \mathrm{~s}<2.5, p \mathrm{~s}$ $>0.10$ ). These findings show that the 4 groups differed from each other, that performance on the distraction trials was worse overall than on the no-distraction trials, and that performance on 30 sec delay trials was worse overall than performance on 15 sec delay trials.

Separate comparisions showed that monkeys with A lesions performed normally overall (Table 2). Averaged across the 15 and $30 \mathrm{sec}$ delays and both distraction conditions (with and without), the A monkeys obtained a score of $76 \%$ correct, and the $\mathrm{N}$ monkeys obtained a score of $73 \%$ correct $(t[4]=0.5, p$ $>0.50$ ). The monkeys with $\mathrm{H}^{\prime}$ lesions were marginally impaired overall $(59 \%$ correct) compared with the normal group $(t[4]=$ $2.4, p<0.08$ ), and significantly impaired relative to the A group $(t[4]=2.6, p<0.05)$. The average score obtained by monkeys in the $\mathrm{H}^{+} \mathrm{A}$ group (63\%) was similar to the score obtained by the $\mathrm{H}^{+}$group $(59 \%$ correct; $t[4]=0.90, p>0.10)$. Moreover, the $\mathrm{H}^{+} \mathrm{A}$ group performed worse than the A group $(t[4]=3.4$, $p<0.05)$. The difference between the $\mathrm{H}^{+} \mathrm{A}$ and the $\mathrm{N}$ group did not reach significance $(t[4]=1.7, p>0.10)$.

\section{Delayed nonmatching to sample retest}

Except for the normal monkeys, monkeys were given delayed nonmatching to sample a second time, approximately 1.5-2 years after it had first been given (range, 18-26 months). Immediately prior to this second test, the $\mathrm{N}$ and the $\mathrm{H}^{+}$groups
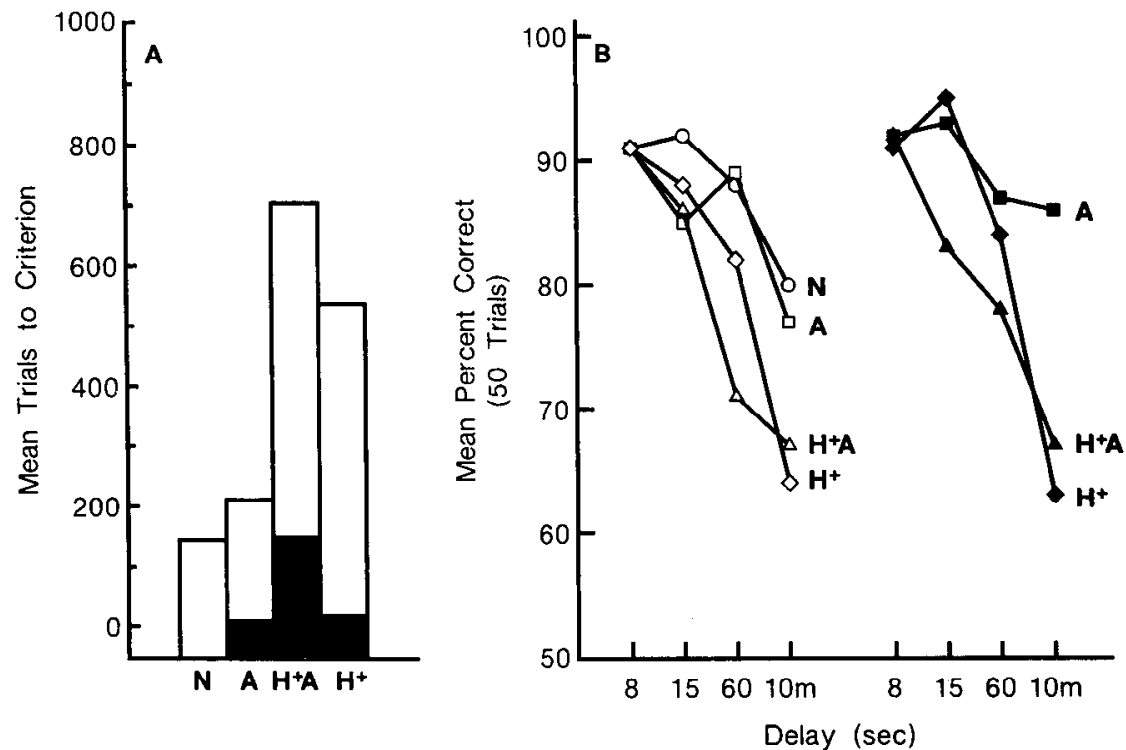

Figure 11. Delayed nonmatching to sample performance on 2 occasions2 months after surgery (open bars and symbols) and again 1.5-2 years after surgery (dark bars and symbols)-by monkeys with lesions of hippocampal formation $\left(\mathrm{H}^{\prime}\right)$ or the amygdala $(A)$ and by monkeys with conjoint lesions of the hippocampal formation and the amygdala $\left(H^{+} A\right)$. Normal monkeys $(N)$ were tested only on the first occasion. $A$, Initial learning of the task with a delay of $8 \mathrm{sec}$. $B$, Performance across delays by monkeys in the 3 operated groups. 


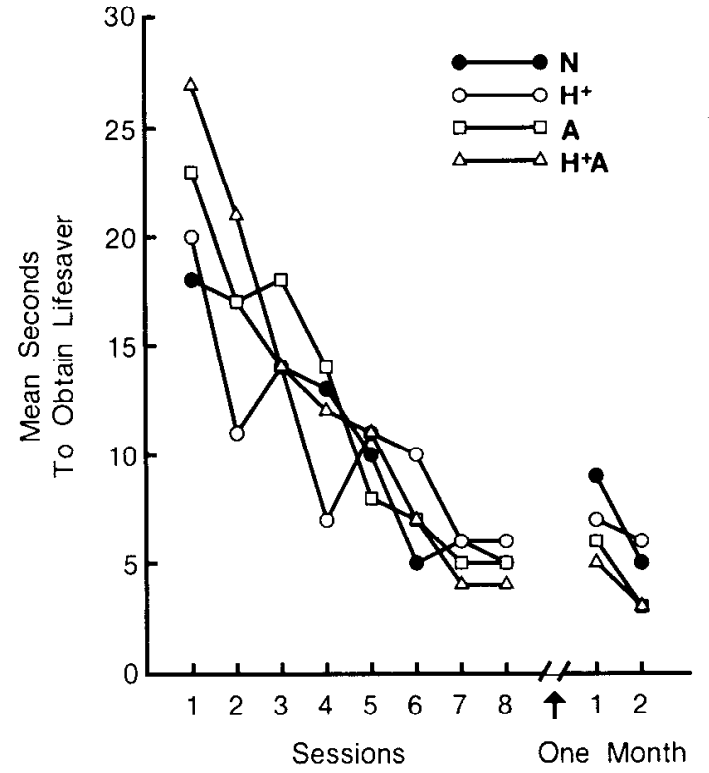

Figure 12. Acquisition of the Lifesaver motor-skill task by normal monkeys $(N)$, by monkeys with lesions of the hippocampal formation $\left(H^{+}\right)$or the amygdala $(A)$, and by monkeys with conjoint lesions of the hippocampus and the amygdala $\left(H^{+} A\right)$.

had been given a different version of the delayed nonmatching to sample task that included a distracting event introduced during some of the delay trials (Zola-Morgan et al., 1989).

Figure $11 \mathrm{~A}$ shows the mean number of trials required to reach learning criterion on the basic $(8 \mathrm{sec})$ task the first (white bars) and second (black bars) times it was given. All groups showed improved learning scores from the first to the second testing. The $\mathrm{H}^{+} \mathrm{A}$ group performed more poorly than the $\mathrm{A}$ group and the $\mathrm{H}^{+}$group $(t \mathrm{~s}>2.6 ; p<0.05)$. Figure $11 B$ shows the effect of increasing the delay interval. An analysis of variance involving 3 groups and 3 delays $(15 \mathrm{sec}, 60 \mathrm{sec}$, and $10 \mathrm{~min})$ revealed a significant effect of group $(F[2,6]=8.9, p<0.05)$, delay $(F[2,12]=17.5, p<0.001)$, and a group $\times$ delay interaction $(F[2,12]=3.1, p=<0.05)$. Separate comparisons between the 3 operated groups, with their scores averaged across the 3 delays (Table 2), revealed that the $\mathrm{II}^{+} \mathrm{A}$ group was impaired relative to the A group $(t[4]=4.4, p<0.01)$. The difference between the $\mathrm{H}^{+}$and $A$ groups fell just short of significance $(t[4]$ $=2.3, p=0.08)$. The $\mathrm{H}^{+}$and the $\mathrm{H}^{+} \mathrm{A}$ groups performed similarly $(p>0.10)$.

On this test, the 3 operated groups performed about the same as they had 1.5-2 years earlier. A 3-way analysis of variance (3 groups, 2 time periods, and 3 delays) revealed significant effects of group and delay $(F \mathrm{~s}[2,6]>9.0, p \mathrm{~s}<0.01)$ but no significant effect of time period $(F[1,6]=4.8, p>0.05)$. When the test was first given, the normal group scored $87 \%$ correct, averaged across the 3 longest delays. The $\mathrm{H}^{+}$group scored $78 \%$ correct on the first test and $81 \%$ correct on the second test; the $\mathrm{H}^{+} \mathrm{A}$ group scored $75 \%$ correct and then $77 \%$ correct; and the A group scored $85 \%$ correct and then $88 \%$ correct.

\section{Lifesaver motor-skill}

All groups learned the Lifesaver task at a normal rate (Fig. 12). A 2-way analysis of variance involving 4 groups and 8 test days revealed a significant effect of session $(F[7,56]=26.2, p<$ 0.001 ), indicating that performance improved across test days.

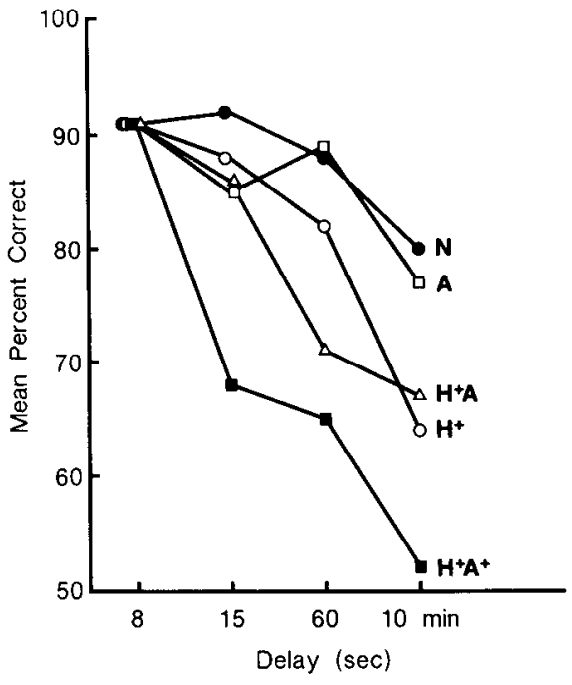

Figure 13. Performance on the nonmatching to sample task of monkeys in the present study and monkeys who had sustained large, bilateral medial temporal resections (the $\mathrm{H}^{+} \mathrm{A}^{+}$lesion) that included the amygdala and the hippocampus, as well as surrounding cortical regions, i.e., the perirhinal cortex, the entorhinal cortex, and the parahippocampal gyrus (Zola-Morgan and Squire, 1985). The $\mathrm{H}^{+} \mathrm{A}^{+}$group was impaired (on the 3 longest delays) relative to every other gorup in the present study.

However, there was no effect of group and no significant group $x$ session interaction $(F \mathrm{~s}<0.88, p \mathrm{~s}>0.50)$. One month after the final session of initial learning, all groups performed equivalently $(F[3,8]=1.53, p>0.10)$.

Further analyses of acquisition and retention performance by each group could not distinguish the normal monkeys from any operated group. For example, the mean number of seconds required to retrieve the Lifesaver on the first trial of each day was similar across groups $\left(\mathrm{N}=13.2 \mathrm{sec}, \mathrm{A}=14.0 \mathrm{sec}, \mathrm{H}^{+}=11.8\right.$ sec, $\left.\mathrm{H}^{+} \mathrm{A}=14.9 \mathrm{sec}\right)$.

\section{Discussion}

Monkeys with bilateral lesions of the amygdaloid complex, without damage to the surrounding cortex (the A lesion), performed normally on the delayed nonmatching to sample task, as well as on 3 other memory tasks (object retention, concurrent discrimination, and delayed response) administered during the $1 \frac{1}{2}$ years after surgery. These animals also performed normally on pattern-discrimination and motor-skill learning, 2 tasks analogous to ones that amnesic patients perform well.

A second group of monkeys with bilateral lesions of the hippocampal formation, in combination with the circumscribed amygdala lesion (the $\mathrm{H}^{+} \mathrm{A}$ lesion), were impaired on the delayed nonmatching to sample task, as well as on object retention, concurrent discrimination, and delayed response. However, the impairment was no greater than in monkeys with lesions of the hippocampal formation alone (the $\mathrm{H}^{+}$lesion).

The performance scores for all the amnesia-sensitive tasks are presented in Table 2. The difference between the scores of the $\mathrm{H}^{+} \mathrm{A}$ group and the $\mathrm{H}^{+}$group did not approach significance for any of the 5 performance measures. On 2 of the measures (concurrent discrimination, delayed response), the most impaired scores were obtained by monkeys in the $\mathrm{H}^{+}$group. On 3 of the measures (delayed nonmatching, object retention, delayed nonmatching retest), the most impaired scores were obtained by monkeys in the $\mathrm{H}^{+} \mathrm{A}$ group. The $\mathrm{H}^{+} \mathrm{A}$ group did per- 
form more poorly than the $\mathbf{H}^{\prime}$ group during the learning portion of 2 of the amnesia-sensitive tasks (delayed response and relearning of delayed nonmatching to sample). It is not clear why the addition of the $\mathrm{A}$ lesion to the $\mathrm{H}^{+}$lesion affected performance on these 2 learning tasks. The additional $A$ lesion did not affect performance on the delay portion of these tasks and did not affect the other performance measures. Figure 13 compares the performance on the delayed nonmatching to sample task of the monkeys in the present study and 4 monkeys studied previously with larger medial temporal removals $\left(\mathrm{H}^{+} \mathbf{A}^{+}\right)$. Separate comparisons between the 3 operated groups $\left(\mathrm{H}^{+}, \mathrm{H}^{+} \mathrm{A}, \mathrm{H}^{+} \mathrm{A}^{+}\right)$, averaging scores across the 3 longest delays, showed that the $\mathrm{H}^{+}$ group (mean, $78 \%$ correct) and the $\mathrm{H}^{+} \mathrm{A}$ group (mean, $75 \%$ correct) each performed significantly better than the $\mathrm{H}^{+} \mathrm{A}^{+}$group (mean, 61\% correct; $p$ s $<0.01$ ).

The finding of normal performance by the A group on the delayed nonmatching to sample task may at first appear at odds with previous reports of mild to moderate impairment on this task following bilateral amygdala lesions (Mishkin, 1978; Murray and Mishkin, 1984; Saunders et al., 1984). In these studies, the amygdala was approached by elevating the frontal poles with the intent of entering the brain at the frontotemporal junction, medial to the rhinal sulcus. As verified by the neurohistological findings, periamygdaloid cortex as well as the anterior portion of the entorhinal cortex were extensively damaged. In addition, it is likely that the adjacent perirhinal cortex also sustained damage (Zola-Morgan et al., 1988).

In the present study, the amygdaloid lesions were made using a stereotaxic approach in combination with a radio frequency lesion maker. In this way, nearly complete lesions of the amygdala were accomplished while sparing the surrounding cortical regions. Monkeys with these lesions were unimpaired on the delayed nonmatching to sample task when it was administered in the same way as in the previous studies. These findings, taken together, suggest that the memory impairment observed previously may be attributable to damage of the cortical regions surrounding the amygdala rather than to direct damage of the amygdala itself. This idea is supported by the present finding that monkeys with the $\mathrm{H}^{+} \mathrm{A}$ lesion were no more impaired than monkeys with removals of the hippocampal formation alone $\left(\mathrm{H}^{+}\right)$. That is, addition of a circumscribed amygdala lesion to a hippocampal lesion did not exacerbate the impairment.

Although damage to the amygdala did not impair memory, the damage did have other behavioral effects. All the operated monkeys in the present study were also involved in a separate study of emotional reactivity (Alvarez-Royo et al., 1988). Emotional reactivity was assessed by rating the responses to a series of inanimate objects presented to the monkeys in their home cages. Every animal in the $\mathrm{A}$ and $\mathrm{H}^{+} \mathrm{A}$ groups exhibited elevated reactivity to the stimulus objects, and they were more reactive than every $\mathrm{H}^{+}$animal. The $\mathrm{H}^{+}$group also exhibited mildly increased reactivity, as compared with a separate group of unoperated monkeys. Thus, the amygdala lesions did not impair memory but did exert other readily detectable behavioral effects.

We conclude that circumscribed bilateral lesions of the amygdala do not impair memory on several tests. Also, adding a selective amygdala lesion to bilateral hippocampal formation damage does not exacerbate the memory impairment produced by the hippocampal formation lesion alone. Studies of memory in monkeys with large medial temporal removals (e.g., the $\mathrm{H}^{+} \mathrm{A}^{+}$ removal) have typically emphasized the importance of both the hippocampus and the amygdala. The present findings suggest that one must look to structures other than the amygdala to account for the severe memory impairment that follows the $\mathrm{H}^{+} \mathrm{A}^{+}$lesion. One possibility is that damage to the cortical regions that surround the amygdala contributes significantly to memory impairment. By this view, damage to these cortical regions contributes to the $\mathrm{H}^{+} \mathrm{A}^{+}$deficit, not damage to the amygdala itself. Consistent with this idea, rather severe memory impairment was observed following lesions of the amygdala made in combination with intended damage to the entorhinal and perirhinal cortex (Murray and Mishkin, 1986). These lesions were intended to be more extensive than the amygdala lesions described in earlier studies (e.g., Murray and Mishkin, 1984).

Recent neuroanatomical studies suggest why damage to the entorhinal and perirhinal cortices could have an impact on memory. The perirhinal cortex and parahippocampal gyrus provide the major source of cortical input to the entorhinal cortex (Insausti et al., 1987), which originates the major projection (the perforant pathway) to the hippocampus and dentate gyrus. Thus, these structures together provide the major system by which information is exchanged between neocortex and the hippocampus. If these structures and connections are the important ones for memory functions of the kind impaired in human amnesia (Squire et al., 1989), then damage to the perirhinal cortex and parahippocampal gyrus alone, without direct damage to the entorhinal cortex, hippocampus, or amygdala, might be expected to produce a severe deficit in memory. Recent evidence shows that such a lesion does produce memory impairment, which is as severe or more severe than the level of impairment associated with $\mathrm{H}^{+} \mathrm{A}^{+}$lesions (Zola-Morgan et al., 1988).

While the present results raise some question about the role of the amygdala in memory, they are nonetheless entirely consistent with the idea that the amygdala plays an important role in other cognitive functions. For example, a number of studies suggest that the amygdala is important in establishing associations between a stimulus and its affective components (Mishkin and Aggleton, 1981; Gaffan and Harrison, 1987) and in bringing together information from different modalities (Murray and Mishkin, 1985).

\section{References}

Aggleton, J. P. (1985) A description of intra-amygdaloid connections in old world monkeys. Exp. Brain Res. 57: 390-399.

Aggleton, J. P., and R. E. Passingham (1981) Syndrome produced by lesions of the amygdala in monkeys (Macaca mulatta). J. Comp. Physiol. Psychol. 95: 961-977.

Aggleton, J. P., R. M. Nicol, A. E. Huston, and A. F. Fairbairn (1988) The performance of amnesic subjects on tests of experimental amnesia in animals: Delayed matching-to-sample and concurrent learning. Neuropsychologia 26: 265-272.

Alvarez-Royo, P., M. Mesches, J. Allen, W. Saltzmann, L. R. Squire, and S. Zola-Morgan (1988) Independence of memory functions and emotional behavior: Separate contributions of the hippocampal formation and the amygdala. Soc. Neurosci. Abstr. 14: 1043.

Amaral, D. G. (1987) Memory: Anatomical organization of candidate brain regions. In Handbook of Physiology-The Nervous System V, J. M. Brookhart and V. B. Mountcastle, eds., American Physiological Society, Bethesda, MD.

Bachevalier, J., J. K. Parkinson, and M. Mishkin (1985) Visual recognition in monkeys: Effects of separate versus combined transections of fornix and amygdalofugal pathways. Exp. Brain Res. 57: 554-561.

Bonin, G., and P. Bailey (1947) The Neocortex of Macaca Mulatta, University of Illinois Press, Urbana, IL.

Davis, R. T., A. A. McDowell, C. W. Deter, and J. P. Steele (1956) Performance of rhesus monkeys on selected laboratory tasks presented 
before and after a large single dose of whole body $x$-radiation. J. Comp. Physiol. Psychol. 49: 20-26.

Gaffan, D., and S. Harrison (1987) Amygdalectomy and disconnection in visual learning for auditory secondary reinforcement by monkeys. J. Neurosci. 7: 2285-2292.

Gaffan, D., E. A. Gaffan, and S. Harrison (1989) Visual-visual association learning and reward-association learning in monkeys: The role of the amygdala. J. Neurosci. 9: 558-564.

Gellerman, L. W. (1933) Chance orders of alternating stimuli in visual discrimination experiments. J. Genet. Psychol. 42: 207-208.

Gloor, P., A. Olivier, and L. F. Quesney (1981) The role of the amygdala in the expression of psychic phenomena in temporal lobe seizures. In The Amygdaloid Complex, Y. Ben-Ari, ed., pp. 489-498, Elsevier/North-Holland, Amsterdam.

Harlow, H. F., and J. A. Bromer (1938) A test-apparatus for monkeys. Psychol. Rec. 19: 434-438.

Hartley, L. H., R. Roger, R. J. Nicolosi, and T. Hartley (1984) Bloodpressure values in Macaca fascicularis. J. Med. Primatol. 13: 183189.

Insausti, R., D. G. Amaral, and W. M. Cowan (1987) The entorhinal cortex of the monkey: II. Cortical afferents. J. Comp. Neurol. 264; 356-395.

Mahut, H., and M. Moss (1984) Consolidation of memory: The hippocampus revisited. In Neuropsychology of Memory, L. R. Squire and N. Butters, eds., pp. 297-315, Guilford, New York.

Mahut, H., M. Moss, and S. Zola-Morgan (1981) Retention deficits after combined amygdala-hippocampal and selective hippocampal resections in the monkey. Neuropsychologia 19: 201-225.

Mahut, H., S. Zola-Morgan, and M. Moss (1982) Hippocampal resections impair associative learning and recognition memory in the monkey. J. Neurosci. 2: 1214-1229.

Mishkin, M. (1978) Memory in monkeys severely impaired by combined but not by separate removal of amygdala and hippocampus. Nature 273: 297-298.

Mishkin, M. (1982) A memory system in the monkey. Trans. R. Soc. London [Biol.] 298: 85-95.

Mishkin, M., and J. Aggleton (1981) Multiple functional contributions of the amygdala in the monkey. In The Amygdaloid Complex, Y. BenAri, ed., pp. 409-420, Elsevier/North-Holland, Amsterdam.

Murray, E. A., and M. Mishkin (1984) Severe tactual as well as visual memory deficits following combined removal of the amygdala and hippocampus in monkeys. J. Neurosci. 4: 2565-2580.

Murray, E. A., and M. Mishkin (1985) Amygdalectomy impairs crossmodal association in monkeys. Science 228: 604-605.

Murray, E. A., and M. Mihskin (1986) Visual recognition in monkeys following rhinal cortical ablations combined with either amygdalectomy or hippocampectomy. J. Neurosci. 6: 1991-2003.

Penfield, W., and B. Milner (1958) Memory deficit produced by bilateral lesions in the hippocampal zone. Arch. Neurol. Psychiatry 79. $475-497$.
Saunders, R. C., E. A. Murray, and M. Mishkin (1984) Further evidence that amygdala and hippocampus contribute equally to recognition memory. Neuropsychologia 22: 785-796.

Scoville, W. B., and B. Milner (1957) Loss of recent memory after bilateral hippocampal lesions. J. Neurol. Neurosurg. Psychiatry 20: 11-21.

Scoville, W. B., R. H. Dunsmore, W. T. Liberson, C. E. Henry, and A. Pepe (1951) Observations on medial temporal lobotomy and uncotomy in the treatment of psychotic states. Preliminary review of 19 operative cases compared with 60 frontal lobotomy and undercutting cases. Res. Pub. Assoc. Res. Nerv. Ment. Dis. 31: 347-369.

Squire, L. R., and S. Zola-Morgan (1983) The neurology of memory: The case for correspondence between the findings for human and non-human primate. In The Physiological Basis of Memory, 2nd ed. J. A. Deutsch, ed., pp. 199-268, Academic, New York.

Squire, L. R., and S. Zola-Morgan (1988) Memòry: Brain systems and behavior. Trends Neurosci. 11: 170-175.

Squire, L. R., S. Zola-Morgan, and K. S. Chen (1988) Human amnesia and animal models of amnesia: Performance of amnesic patients on tests designed for the monkey. Behav. Neurosci. 102: 210-221.

Squire, L. R., A. P. Shimamura, and D. G. Amaral (1989) Memory and the hippocampus. In Neural Models of Plasticity, John Byrne and William Berry, eds., Academic, New York (in press).

Szabo, J., and W. M. Cowan (1984) A stereotaxic atlas of the brain of the cynomolgus monkey (Macaca fascicularis). J. Comp. Neurol. 222: $265-300$.

Weiskrantz, L. (1956) Behavioral changes associated with ablation of the amygdaloid complex in monkeys. J. Comp. Physiol. Psychol. 49: $381-391$.

Zola-Morgan, S., and L. R. Squire (1984) Preserved learning in monkeys with medial temporal lesions: Sparing of motor and cognitive skills. J. Neurosci. 4: 1072-1085.

Zola-Morgan, S., and L. R. Squire (1985) Medial temporal lesions in monkeys impair memory in a variety of tasks sensitive to human amnesia. Behav. Neurosci. 99: 22-34

Zola-Morgan, S., and L. R. Squire (1986) Memory impairment in monkeys following lesions of the hippocampus. Behav. Neurosci. 100: $165-170$.

Zola-Morgan, S., L. R. Squire, and D. G. Amaral (1986) Human amnesia and the medial temporal region: Enduring memory impairment following a bilateral lesion limited to field CA1 of the hippocampus. 6: 2950-2967.

Zola-Morgan, S., L. K. Squire, and D. G. Amaral (1988) Amnesia following medial temporal lobe damage in monkeys: The importance of the hippocampus and adjacent cortical regions. Soc. Neurosci. Abstr. 14: 1043.

Zola-Morgan, S., L. R. Squire, and D. G. Amaral (1989) Lesions of the hippocampal formation hut not lesions of the fornix or the mammillary nuclei produce long-lasting memory impairment in monkeys. J. Neurosci. 9: 897-912. 